\title{
ESTUDO DAS PRECIPITAÇÕES PLUVIAIS NO MUNICÍPIO DE BELÉM-PA, ATRAVÉS DA DISTRIBUIÇÃO GAMA
}

ROSEMIRO DOS SANTOS GALATE

Engenheiro Agrônomo

Orientador: Prof. Dr. CLÓVIS POMPILIO DE ABREU

Dissertação apresentada à Escola Superior de Agricultura "Luiz de Queiroz", da Universidade de São Paulo, para obtenção do título de Mestre em Agronomia, Área de Concentração: Estatística $\theta$ Experimentação Agronômica.

PIRACICABA

Estado de São Paulo - Brasil

Setembro - 1987 


\section{AGRADECIMENTOS}

Ao Dr:Clövis Pompilio de Abreu, professor do Departamento de Matemātica e Estatística da Escola Superior de Agricultura "Luiz de Queiroz", pela orientação e amizade. Ao Dr. lzaias Rangel Nogueira, pelo incentivo e sabedoria.

Ao Dr.Humberto de Campos, professor e Diretor da ESALQ, pelos ensinamentos e apoio recebidos durante a realização deste curso.

Ao Dr: Décio Barbin, professor e Chefe do Departamento de Matemätica e Estatística, pelos ensinamentos e am izade.

Ao professor Francisco Barreira Pereira, professor da Faculdade de Ciências Agrärias do Pará pelo apoio e incentivo para realização deste curso.

Aos demais professores do Departamento de Matemātica e Estatítica da ESALQ, pelos ensinamentos e dedicaçao.

A Faculdade de Ciências Agrärias pela oportunidade da realização deste curso.

Aos colegas do Curso de Pós-Graduação, pelo espirito dé solidariedade e comparheirismo. 


\begin{abstract}
A todos aqueles, que de uma forma ou de outra souberam me inspirar, incentivar, ajudar e compreender, para que este trabalho pudesse ser realizado.
\end{abstract}




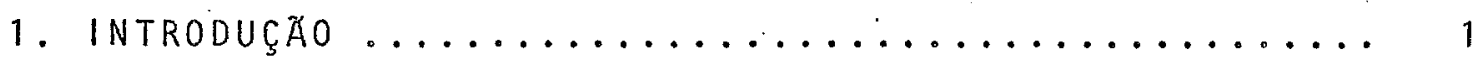

2. REVISÄO DE LITERATURA .................... 3

3. MATERIAL E METODOS .......................

3.1. Material ..........................

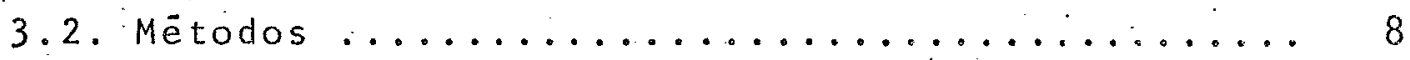

3.2 .1$. Considerações ................. 8

3.2.2. Estimativas dos parâmetros ......... 11

3.2.2.1. Método da mäxima verossimelhan $\S a \ldots \ldots \ldots \ldots \ldots \ldots \ldots \ldots \ldots \ldots \ldots$

3.2.3. Estimativas das variâncias e covariância dos estimadores e intervalos de con

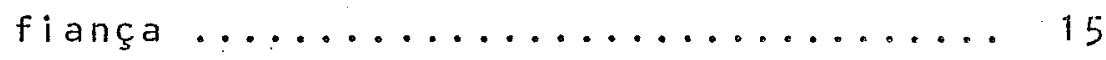

3.2.4. Cälculo das estimativas das precipita-

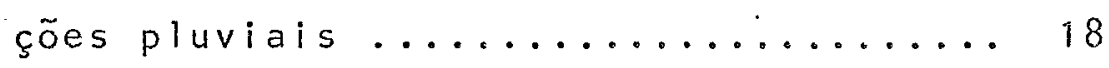

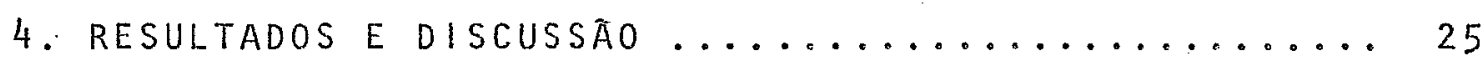

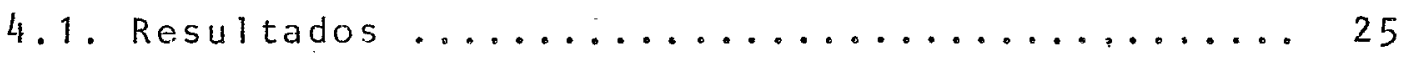

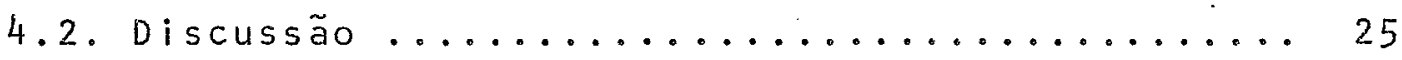

4.2.1. Estimativas de $\alpha$ e $\beta \ldots \ldots . \ldots . \ldots 25$

4.2.2. Teste de aderência .............. 28 
4.2.3. Estimativas de diferentes alturas plu-

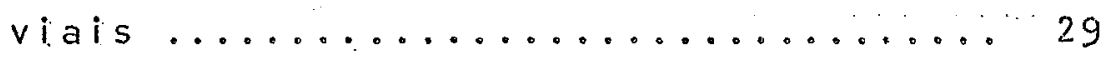

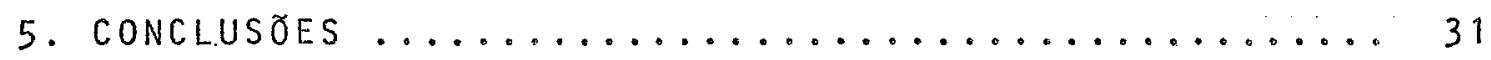

REFERENCIAS BIBLIOGRAFICAS ........................ 32

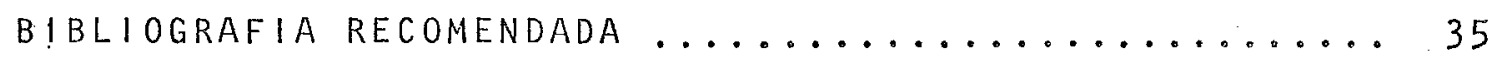

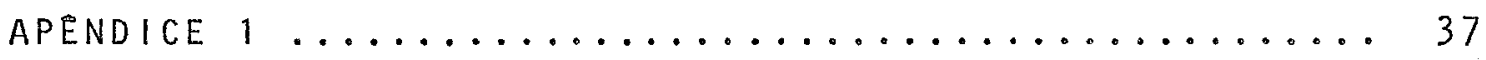

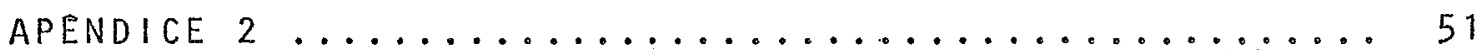

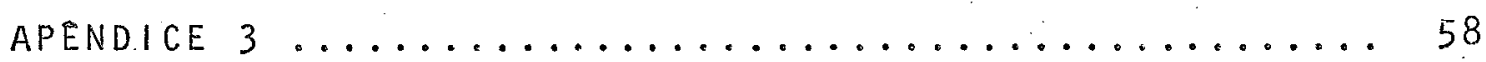


$v i \mathrm{i}$ ESTUDO DAS PRECIPITACÕES PLUVIAIS NO MUNICÍPIO DE BELÉM-PA, ATRAVÉS DA DISTRIBUIÇÃO GAMA

\author{
Autor: ROSEMIRO DOS SANTOS GALATE \\ orientador: PROF. DR. CLOVIS POMPILIO DE ABREU
}

RESUMO

Neste trabalho aplicou-se a distribuição gama incomple ta aos dados de precipitação pluvial, para o município de Belēm-pA, durante 34 anos, de 1953 a 1986, referentes aos períodos dos 1-3, 1-6, 1-9, $1-12,1-15,1-18,1-21,1-24,1-27$ e total de cada mês, tomados em mm.

As anälises estatísticas foram feitas num computador PC 2002, do Centro de Informātica na Agricultura. (CIAGRI) da ESALQ/USP. Na aplicação do algoritmo de Newton-Rapson foram utilizadas as sub-rotinas RTNI, FCT e Gama.

Foi desenvolvido o método da mäxima verossimi lhança pa raestimar os párāmetros $\alpha$ e $\beta$ da distribuição gama.

* Determinou-se estimativas das variancias dos estimadores, e intervalos de confiança foram construidos para os parametros $\alpha$ e $\beta$ considerando o nivel de $90 \%$ de probabilidade.

No ajustamento dos dados amostrais de chuva, dos períodos estudados, foi usado o teste $\chi^{2}$.

Na determinaçäo das estimativas das precipi- 
pitações pluviais, associadas a 19 níveis de probabilidade, foi considerado o modelo simples, para o caso da amostra não conter valores nulos, e o modelo misto, no caso da amostra conter valores nulos.

Para o modelo simples, as estimativas: das precipitações foram calculadas pela solução da equação:

$$
\begin{aligned}
g\left(t_{i}\right)= & \frac{t^{\bar{\alpha}}}{\hat{\alpha} \Gamma(\hat{\alpha}) e^{t}}\left[1+\frac{t}{(\hat{\alpha}+1)}+\frac{t^{2}}{(\hat{\alpha}+1)(\hat{\alpha}+2)}+\right. \\
& \left.+\frac{t^{3}}{(\hat{\alpha}+1)(\hat{\alpha}+2)(\hat{\alpha}+3)}+\cdots\right]-F=0
\end{aligned}
$$

obtida através da aplicação do algórítmo de Newton-Raphson.

Para o modelo misto, as estimativas das precipitações foram obtidas através da equação

$H(t)=\hat{Q}+(1-\hat{Q}) F(t)-G=0$, que tambēm foi resolvida pelo método de Newton-Raphson.

os resultados obtidos referentes a todos os períodos são apresentados e são feitas anälises para as estimativas dos parâmetros $\alpha$ e $\beta$. Foram preparadas tabelas de estimação de precipitação em 19 niveis de probabilidade.

Com exceção dos períodos de $1-3$, dos meses de agosto, outubro e novembro, a distribuição gama apresentou resultados que estão de acordo comosobservados, em razão da hipötese nula não ser rejeitada em $97,48 \%$ dos períodos es tudados, o que comprova a eficäcia da distribuição gama incompleta para as estimativas de quantidades de chuva para o município de Belëm-PA. 


\title{
A STUDY ON THE RAINFALL MEASUREMENTS IN BELËM (PARÁ COUNTY) THROUGH GAMMA DISTRIBUTION
}

\author{
Author: ROSEMIRO DOS SANTOS GALATE \\ Adviser: PROF. DR. CLOVIS POMPILIO DE ABREU
}

SUMMARY

In this work the incomplete gamma distribution was applied on the rainfall data to Belëm-PA, county, in a period of 34 years, from 1953 to 1986 , refering. on the periods $1-3,1-6,1-9,1-12,1-15,1-18,1-21,1-24,1-27$ and monthly, each month taken in milimeters.

The statistical analysis were elaborated in a PC 2002 eletronic computer at the Centro de Informātica na Agricultura (CIAGRI)/ESALQ/USP. In the application at the Newton-Rapson's method was used the RTNI, FCT and Gamma subroutines.

The method of maximum likelihood was applied to the estimation of parameters $\alpha$ and $\beta$ gamma distribution.

Variance of the estimators were determinated and confidence interval were built for the parameters.

The goodness of fit was evaluated by chi-square test. In the determination of the estimation of rainfall data in 19 levels of probabilities, was considered a. simple model if the sample doesn't have null values and a 
mixed model if the sample contains a null values.

In the simple model, the rainfall data estimation is done by the equation:

$$
\begin{aligned}
g\left(t_{i}\right)= & \frac{t^{\hat{\alpha}}}{\hat{\alpha} \Gamma(\hat{\alpha}) e^{t}}\left[1+\frac{t}{(\hat{\alpha}+1)}+\frac{t^{2}}{(\hat{\alpha}+1)(\hat{\alpha}+2)}+\right. \\
& \left.+\frac{t^{3}}{(\hat{\alpha}+1)(\hat{\alpha}+2)(\hat{\alpha}+3)}+\ldots\right]-F=0 .
\end{aligned}
$$

taken from Newton-Raphson's method.

For the mixed model, the estimatiors was done by the equation

$H(t)=\hat{Q}+(1-\hat{Q}) F(t)-G=0$

also taken from Newton-Raphson's method.

Results are presented refering to all periods studied, and analysis on the estimation of parameters $\alpha$ and $\beta$. Tables of probabilities of amount of rainfall were calculated in 19 . levels.

Excepting of the periods of $1-3$ of the months August, october and November. The gamma distribution showed results according to the observed, since the null hypothesis was not rejected in $97,48 \%$ of the studied periods. It demonstrates the efficiency of the incomplete gamma distribution to the estimates of amount of precipitation in Belēm-PA, county. 


\section{MTRODUĞO}

No município de Belém - PA, quando da realização de planejamentos agrícolas que envolve precipitação, é usual a aceitação da mëdía pluviomëtrica como valor provável para estimar a quantidade de ägua proveniente das chuvas.

Esta medida estatística não fornece um: . bom indice de avaliação de chuva, devendo ser utilizada somente para a precipitação anual, já que sua distribuição se aproxima da normal, entretanto para periodos pequenos, como mensais ou inferiores, a distribuição desses dados se afasta muito da normal. Assim é necessário se considerar uma outra metodologia na anălise de precipitações.

Värios estudos têm mostrado que a distribuição gama incompleta se ajusta bem para representar dados de chuva.

As produções agrícolas são funções de diferentes fatores, entre os quais, os fatores climäticos, tais como quantidade totai de chuva, distribuição pluviomētrica, temperatura e umidade relativa do ar. Dessas variáveis, a precipitação pluvial è o elemento regulador na agricultura, sendo que a quantidade de chuva que cai em uma localidade 
determina o tipo de atividade agricola a ser desenvolvida. Entretanto, a exploração de determinadas culturas é mais dependente do curso anual de precipitação que do volume de ägua caido anualmente. Portanto, com o estudo da distribuição de chuva é possivel fornecer informações que visem reduzir as conseqüências causadas pelas flutuações de chuva de ano para ano responsáveis por variações na produção.

Desta forma, é de grande importāncia para aquele municipio, um estudo para obtenção de quantidades prováveis de chuva baseado em dados de anos anteriores.

o objetivo do presente trabalho è determinar, através da distribuição gama incompleta, estimativas de diferentes alturas pluviais para Belën - PA, no sentido de aum xiliar o trabalho dos responsáveis pelos projetos agrícolas ou outras atividades economicas, de maneira a se obter um me Ihor aproveitamento de ägua na agricultura. 


\section{REVISÃO DE LITERATURA}

$$
\text { BARGER \& THOM (1949) estudaram as distribuiçōes }
$$

de freqüência dos dados compreendidos entre uma e dezesseis semanas, observaram que para períodos pequenos, como atë qua tro semanas, o aspecto da curva sugere uma exponencial negativa no ajustamento e, a medida que aumenta o período, a tendência da curva é ser unimodal assimétrica, para depois se aproximar da curva normal, em função dessas características os au tores usaram a distribuição gama; cuja curva admite tal flexibi lidade. Para a estimação dos parâmetros, os autores desenvolveram um método aproximado.

FRIEDMAN \& JANES (1957), fizeram um estudo de talhado da estimativa de probabilidade de precipitação pluvial. Quanto ao uso da distribuição gama, obtiveram as mesmas conclusões de BARGER \& THOM. Os autores estudando o tamanho da amostra, para que esta seja representativa acham que são necessārios no mínimo dados de 30 anos.

THOM (1968) estudando a eficiência dos estimado res obtidos, pelo método dos momentos em comparação com os obtidos pelo. mētodo da mäxima verossimelhança, verificou que para $\alpha=1$ a eficiência de $\hat{\alpha}=0,39$ e de $\hat{\beta}=0,51$, para $\alpha=10$ a eficiência de $\hat{\alpha}=0,88$ e de $\hat{\beta}$ $=0,89$. 
f BARGER et azii (1.959), realizaram um estudo com dados pluviométricos de duas e très semanas, e verificaram que a distribuição gama se ajustou aos dados.

K WEAVER \& MILLER (1967), efetuaram um trabalho e mostraram que a distribuicão gama se ajusta bem para representar dados de precipitação.

STROMMEN \& HORSFIELD (1969), publicaram através do Departamento de Agricultura dos Estados Unidos, tabelas de probabilidades de precipitação pluvial mensal para 23 estados, utilizando a distribuição gama. Foi empregado o processo aproximado de Thom nas es timações dos parâmetros e não fizeram referência sobre o tes te de ajustamento. Os autores deram importância somente à discussão dos resultados, não dando ênfase a metodologia usada.

AMARAL \& SILVA (1970) publicaram uma tabela que dá as probabilidades de diferentes quantidades de chuva em periodos de cinco dias para a Cidade de Pelotas - RS. Os autores não apresentaram detalhes teöricos a respeito, do mëtodo adotado na elaboraça da referida tabela contida no trabalho. $x$

HARDEE (1971), encontrou que para alguns meses de baixa precipitacão, a distribuiç̃o gama não foi bem sucedida.

ELLIS (1972) estudando dados de precipitação de Manaus - AM, obteve um bom ajustamento da distribuiça normal para os dados anuais. No estudo dos dados mensais 
empregou a distribuição gama, devido ao aspecto assimētrico da curva. 0 ajustamento desses dados mensais foi feito pelo teste de Kolmogorov-smirnov. 0 autor não entrou em detalhes estatísticos-matemāticos da obtenção dos resultados.

VIVALDI (1973) estudando os dados pluviométricos de ltaguaí-RJ, dá ênfase aos aspectos teóricos dos mëtodos utilizados na obtenção das estimativas dos parâmetros. O autor concluiu que o método da mäxima verossimelhan ca é mais eficiente.

PORTO et azii (1979) fizeram uma ànálise sobre a utilizạ̄ão da distribuịão gama incompleta, com base ém 55 anos de dados das estacöes meteorolögicas de Santana do Ipanema e Palmeira dos indios - Al em estimativa de chuva. Foi usado um computador para estimar a lâmina mensal e anual associada a sete níveis de probabilidade. Utilizaram uma amostra de 30 anos e comparando com a seqüência dos 25 anos seguintes; Observaram que no período chuvoso a amostra cons tituída de 30 anos é satisfatória, todavias para o período seco pode não ser representativa. Constataram ainda que a mëdia aritmética de precipitacão mensal e anual, baseada em 30 anos não deve ser considerada como indice em planejamento e que o tamanho da amostra é tão importante quanto a tipo de distribuição a ser usada.X 0 s autores näo fizeram maiores co mentärios a respeito da metodologia empregada.

ARRUDA \& PINTO (1980) estudaram a distribuicao de freqüencia de pêntadas de dados de precipitaçäo na 
Região de Campinas - SP, três modelos matemáticos foram usa dos (exponencial, distribuicão gama e normal transformada) para estimação dos parâmetros. Os autores observaram que para periodos pequenos, como cinco dias, em que a. curva é do tipo de um $j$ invertido, Pode-se utilizar o mëtodo exponencial, devido se obter de forma mais räpida os estimadores. No ajustamento dos dados foi usado o teste de KolmogorovSmirnov. 


\section{3. material e metodos}

\section{1. Material}

Os dados de precipitação pluvial foram fornecidos pelo Instituto Nacional de Meteorologia (INMET).

As observaçōes referem-se as precipitaçöes diärias, coletadas pela Estação Climatolögica Principal de Belēm, localizada na ärea da Empresa Brasileira de Pesquisa Agropecuäria (EMBRAPA), Belëm - PA, latitude $1^{\circ} 27^{\prime}$, longitude $48^{\circ} 28^{\prime}$ W.G. e altitude $24 \mathrm{~m}$, durante 34 anos no periodo de 1953 a 1986, tomadas em milímetros.

Para as anälises estatísticas dos dados 'utiIizou-se o computador PC 2002 da Microtec, do centro de Informātica na Agricultura (ClAGRI) da Escola Superiorde Agri-. cultura "Luiz de Queiroz", da Universidade de São Paulo. Estas informaçöes possibilitaram o escudo do ajustamento da distribuição gama aos dados, correspondentes a 10 periodos dentro de cada mês, com exceção de fevereiro onde estudou-se nove períodos.

Nos anos bissextos o mês de fevereirofoi re- 
duzido para 28 dias de acordo com o procedimento usado por AMARAL (1968), que consiste em. multiplicar os totais!dos periodos por $28 / 29$.

\subsection{Métodos}

A metodologia usada na determinação das estimativas dos parâmetros da distribuição gama, variância e covariância dos estimadores, quantidades de chuva associadas a 19 niveis de probabilidades e o ajustamento da distribuição da amostra à distribuição gama, para melhor compreensão é apresentada a seguir:

\subsubsection{Consideraçöes}

A distribuição gama é derivada da função gama conhecida, definida por:

$$
\begin{aligned}
& f_{Y}(y, \alpha)=y^{\alpha-1} \cdot e^{-y}: d y \quad((0, \infty)(y), \quad \text { fazendo } \\
& y=\frac{x}{\beta} ; \quad y=0 ; x=0 ; \quad y=\infty ; x=\infty ; d y=\frac{d x}{\beta} ; \text { tem-se } \\
& f_{X}(x, \alpha, \beta)=\frac{1}{\beta^{\alpha}} x^{\alpha-1} \cdot e^{-(x / \beta)} \cdot d x \quad 1(0, \infty)(x)
\end{aligned}
$$

Esta função, representará uma função de densidade, se multiplicada por uma constante $K$ de tal forma que $k_{0} f^{\infty} \frac{1}{\beta^{\alpha}} x^{\alpha-1} \cdot e^{-(x / \beta)} \cdot d x=1$, então resolvendo a integral 
9.

encontra-se o valor de $k=\frac{1}{\Gamma(\alpha)}$. Conclui-se que se $x$ for uma variävel aleatória continua, com $(0<X \infty)$, segue a distribuição gama com parámatros $\alpha>0$ e $\beta>0$.

$f_{X}(x)=\frac{1}{\Gamma(\alpha) \beta^{\alpha}} x^{\alpha-1} \cdot e^{-(x / \beta)} 1(0, \infty)(x)$

A função de distribuição acumulada serā:

$P(x \leqslant x)=F(x)=\frac{1}{\Gamma(\alpha) \beta^{\alpha}} \int_{\alpha}^{x} U^{\alpha-1} e^{-(U / \beta)} \cdot d u$

Onde:

$X=$ variāvel aleatōi a contínua que representa. a grandeza do evento;

$F(x)=$ probabilidade de ocorrência de um va-

lor $x \leqslant x$;

$$
\begin{aligned}
& \alpha=\text { parânetro de formá } \\
& \beta=\text { parâmetro de escala. } \\
& e=\text { base do logaritmo neperiano } \\
& a=\text { origem. } \\
& \Gamma(\alpha)=\text { função gama incompleta }
\end{aligned}
$$

Desde que valores negativos de chuva sãa impossiveis, é conveniente, para o presente trabalho, forçar a curva passar pela origem dos eixos coordenados. A equação (4) $\operatorname{com} a=0$ fica:

$F(x)=\frac{1}{\Gamma(\alpha) \beta^{\alpha}}=\cdot \int^{x} u^{\alpha-1} \cdot e^{-(U / \beta)} \cdot d u$ 
chuva.

Se $X$ tem uma distribuição gama com parâmetros $\alpha$ e $\beta$, a função geradora de momentos è dada por:

$\phi_{X}(t)=(1-\beta t)^{-\alpha}, \quad$ com $t<\frac{1}{\beta}$

A partir da f.g.m. determinam-se os dois momentos populacionais de grande importância para o nosso estudo que são:

a) o primeiro momento em relação a origem, que $\bar{e}$ a média $m=\alpha \beta$

b) 0 segundo momento em relação a mẹdia, que

é a variancia $\mu_{2}=\sigma_{x}{ }^{2}=\alpha \cdot \beta^{2}$.

A partir da förmula de recorrência

$\mu_{n}+1=\sigma_{x}^{2} \cdot \frac{d \mu_{n}}{d(m)}+n \cdot \sigma_{x}^{2} \mu_{n-1}$,

obtemos momento de ordem superior ao segundo centrado na média, desses interessa o terceiro para calcular o coeficiente de assimetria,

$a_{3}=\frac{\mu_{3}}{\sqrt{\mu^{3}}}=\frac{2}{\sqrt{\alpha}}$,

Observa-se que à medida que $\alpha$ aumenta adistribuição gama tende a ser simétrica. 


\subsubsection{Estimativas dos parâmetros}

Em trabalhos realizados com a aplicação da distribuição gama em dados pluviomētricos, um grande problema encontrado; é a estimação dos parâmetros $\alpha$ e $\beta$. Portanto, värios mētodos podem ser usados, taís como o método dos quadrados mínimos, o método dos momentos e o da mäxima verossimelhança. Porém, todos possuem limitações de uso, seja por problemas matemáticos, ou por produzirem estimativas ineficientes. Um dos métodos mais indicado ë o de máxima verossimelhança THOM (1958).

\subsubsection{Método da mäxima verossimelhança}

Admita que uma população tenha função de densidade que contenha um parâmetro populacional $\theta$, a ser esti mado. Então, a função de densidade pode ser denotada por $f(x, \theta)$. Considerando que haja $n$ observaçöes independentes, $x_{1}, x_{2}, \ldots, x_{n}$, a função de densidade conjunta dessas observações è:

$$
f\left(x_{1}, x_{2}, \ldots, x_{n} ; \theta\right)=f\left(x_{1}, \theta\right) . \quad f\left(x_{2}, \theta\right) \ldots f\left(x_{n}, \theta\right)(11)
$$

Representada por

$L\left(x_{1}, x_{2}, \ldots, x_{n} ; \theta\right)=\prod_{i=1}^{n} f\left(x_{i}, \theta\right)$, que è chamada de

verossimel hança.

Então a mäxima verossimelhança pode ser obti- 
da, fazendo a derivada de $L\left(x_{1}, x_{2}, \ldots, x_{n} ; \theta\right)$ em relação a $\theta$ e igualando-se a zero. Para o uso desse método è conveniente, inicialmenteachar o logaritmo e depois derivar. observe que $\theta$ è um vetor formado pelos parâmetros da distribuição a ser usada $\underline{\sim}=\left(\theta_{1}, \theta_{2}, \ldots, \theta_{k}\right)$, resolvendo o sistema tem-se:

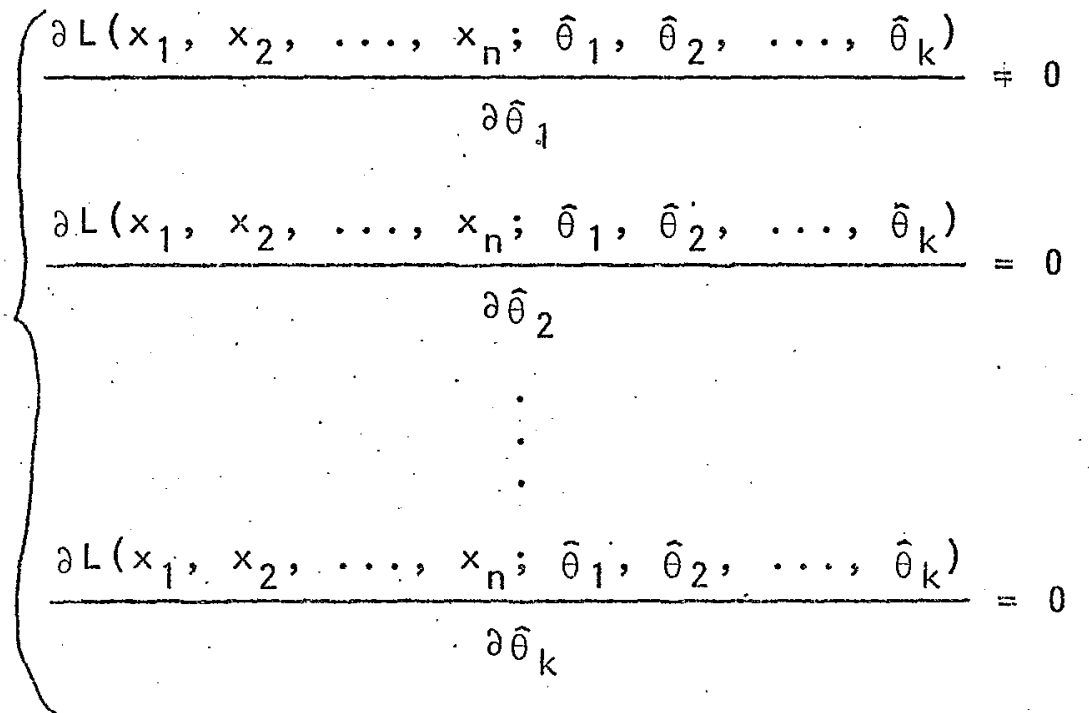

$\hat{\theta}_{1}, \hat{\theta}_{2}, \ldots, \hat{\theta}_{k}$, são denominados, estimadores de máxima verossimilhança dos parâmetros $\theta_{1}, \theta_{2}, \ldots, \theta_{k}$.

No presente estudo a função de densidade ë:

$$
f_{X}(x)=\frac{1}{\Gamma(\alpha) \beta^{\alpha}} x^{\alpha-1} \cdot e^{-(x / \beta)},(0, \infty)(x)
$$

$$
\begin{aligned}
& L\left(x_{1}, x_{2}, \ldots, x_{n} ; \alpha, \beta\right)=\frac{1}{[\Gamma(\alpha)]^{n} \beta^{n \alpha}}\left(x_{1}, x_{2}, \ldots x_{n}\right)^{\alpha-1} . \\
& -\sum_{i=1}^{n} x_{i}
\end{aligned}
$$


13.

$\ln L\left(x_{1}, x_{2}, \ldots, x_{n} ; \alpha, \beta\right)=\ln \left[[\Gamma(\alpha)]^{-n_{\beta}-n \alpha}\left(x_{1}, x_{2}, \ldots\right.\right.$

$\left.\left.\cdot x_{n}\right)^{\alpha-1} e^{\frac{-\sum_{i=1}^{n} x_{i}}{\beta}}\right]$

$\ln L\left(x_{1}, x_{2}, \ldots, x_{n} ; \alpha, \beta\right)=-n \ln \Gamma(\alpha)-n \alpha \ln \beta+(\alpha-$

-1) $\sum_{i=1}^{n} \ln x_{i}-\frac{\sum_{i=1}^{n} x_{i}}{\beta}$

$\left\{\begin{array}{c}\frac{\partial \ln L\left(x_{1}, x_{2}, \ldots, x_{n}, \alpha, \beta\right)}{\partial \alpha}=-n \frac{\Gamma^{i}(\hat{\alpha})}{\Gamma(\hat{\alpha})}-n \ln \hat{\beta}+\sum_{i=1}^{n} \ln x_{i} \neq \\ =0 \quad \frac{n}{\partial \beta}=-n \frac{\hat{\alpha}}{\hat{\beta}}+\frac{\sum_{i=1} x_{i}}{\hat{\beta}^{2}}=0\end{array}\right.$

$\left\{\begin{array}{l}n \frac{\Gamma^{\prime}(\hat{\alpha})}{\Gamma(\hat{\alpha})}+n \ln \hat{\beta}-\sum_{i=1}^{n} \ln x_{i}=0 \\ n \bar{\alpha} \frac{n=1}{i=} x_{i} \\ \frac{\bar{\beta}^{2}}{\bar{\beta}}=0\end{array}\right.$

$\frac{n \hat{\alpha}}{\hat{\beta}}=\frac{\sum_{i=1}^{n} \cdot x_{i}}{\hat{\beta}^{2}}=0 \quad, \quad \hat{\beta}=\frac{\bar{x}}{\hat{\alpha}}$

Em (2,2) dividindo-se ambos os membros por $n$

e substituindo $\hat{\beta}$ por $\bar{X} / \hat{\alpha}$, tem-se:

$\ln \hat{\alpha}-\frac{\Gamma^{\prime}(\bar{\alpha})}{\Gamma(\hat{\alpha})}=\ln \bar{x}-\frac{1}{n} \sum_{i=1}^{n} \ln x$ 
A expressão $\Gamma^{\prime}(\hat{\alpha}) / \Gamma(\hat{\alpha})$ é chamada função di gama de $\hat{\alpha}$, representada por $\psi(\hat{\alpha})$, suas derivadas $\psi^{\prime}(\hat{\alpha})$, $\psi^{\prime \prime}(\hat{\alpha})$, são chamadas funções trigamas, tetragamas, etc. A função digama aparece tabelada em algumas pubicacões, mas para poucos valores (MILNE, 1968). Portanto, värios desenvolvimentos em série tem sido feito a seu respeito, como:

$\psi(\alpha)=\frac{1}{2} \ln \alpha(\alpha+1)+\frac{1}{6}\left(\frac{1}{\alpha}-\frac{1}{\alpha+1}\right)-\frac{1}{90}\left(\frac{1}{\alpha^{3}}-\frac{1}{(\alpha+1)^{3}}\right) \cdots$ encontrado em MILNE (1968).

Outro desenvolvimento foi dadopor THOM (1958) $\psi(\alpha)=\ln (\alpha)-\frac{1}{2 \alpha}-\sum_{k=1}^{m} \frac{B 2 k}{\left(2 k \alpha^{2 k}\right)}+R m, \quad \alpha \geqslant 1$ onde $B_{k}$-são os nümeros de Bernoulli, $B_{2}=\frac{1}{6}, B_{4}=\frac{1}{30}, \ldots$ e $R_{m}$ é o resto apös $m$ ternos, avaliado pela inequação

$$
\left|R_{m}\right|<\frac{\left|B_{2 m+1}\right|}{(2 m+2)^{2 m+2}} \text {. }
$$

A equação (25) pode ser representada por:

$$
\ln (\hat{\alpha})-\psi(\hat{\alpha})=\ln \bar{x}-\frac{1}{n} \sum_{i=1}^{n} \ln x_{i}, \text { fazendo-se }
$$

$$
\begin{aligned}
& A=\ln \bar{x}_{-} \frac{1}{n} \sum_{i=1}^{n} \ln x_{i}, \quad \text { fica } \\
& \ln (\hat{\alpha})-\psi(\hat{\alpha})=A .
\end{aligned}
$$


15.

demonstrado por THOM (1958), onde a estimativa do. parâmetro $\alpha$ é obtida, após vārias deduções, da equação seguinte:

$12\left(\ln \bar{x}-\frac{1}{n} \sum_{i=1}^{n} \ln x_{i}\right) \hat{\alpha}^{2}-6 \hat{\alpha}-1=0$

$12 A \hat{\alpha}^{2}-6 \hat{\alpha}-1=0$

$\hat{\alpha}=\frac{1+\sqrt{1+4 A / 3}}{4 A}$

Onde:

$$
\begin{aligned}
& \bar{x}=\text { mēdia das } n \text { observaçöes; } \\
& n=\text { nümero de observações; } \\
& x_{i}=\text { altura de chuva em } \mathrm{mm} .
\end{aligned}
$$

3.2.3. Estimativas das variâncias e covariancia dos estimadores e intervalos de comfiança

HOFFMANN \& VIEIRA (1977) e THOM (1958), em suas pesquisas sobre a matriz de variância e covariancia, dos estimadores, concluiram que é definida por:

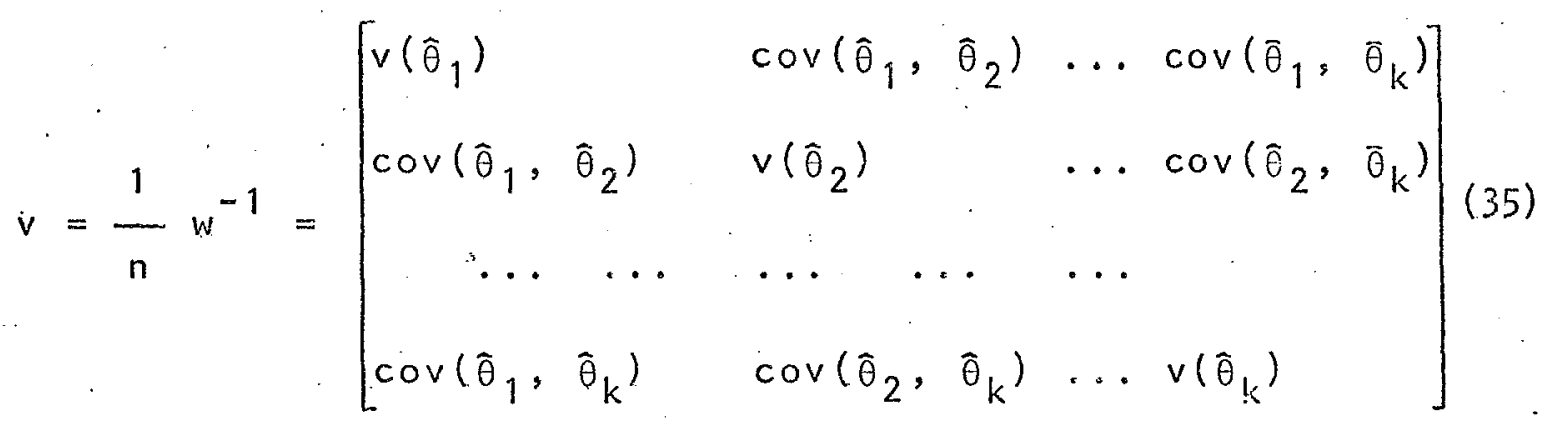

Sendo $n$ o tamanho da amostra e w uma matriz $K \times K$ simētrica, cujos elementos são dados por: 
$w_{i j}=-E\left[\frac{\partial^{2} \ln L\left(x_{1}, x_{2}, \ldots, x_{n} ; \hat{\theta}_{1}, \hat{\theta}_{2}, \ldots, \hat{\theta}_{k}\right)}{\partial \bar{\theta}_{i} \partial \tilde{\theta}_{j}}\right]$

onde:

$$
\begin{aligned}
\mathbf{i} & =1,2, \ldots, k \\
\mathbf{j} & =1,2, \ldots, k .
\end{aligned}
$$

A matriz resultante é denominada de matriz de informação:

$$
W=\left[\begin{array}{ccccc}
w_{11} & & w_{12} & \ldots & w_{1 k} \\
w_{21} & & w_{22} & \ldots & w_{2 k} \\
\ldots & \ldots & \ldots & \cdots & \ldots \\
w_{k 1} & & w_{k 2} & \ldots & w_{k k}
\end{array}\right]_{k k}
$$

Onde:

$$
k=\text { nümero de parâmetros. Para o presente tra }
$$

balho tem-se:

$$
\begin{aligned}
& W_{i j}=-E\left[\frac{\partial^{2} \ln L\left(x_{1}, x_{2}, \ldots, x_{n} ; \hat{\alpha}, \hat{\beta}\right)}{\partial \hat{\alpha}: \partial \hat{\beta}}\right] \\
& w_{11}=-E\left[\frac{\partial^{2} \ln L\left(x_{1}, x_{2}, \ldots, x_{n} ; \hat{\alpha}, \hat{\beta}\right)}{\partial \hat{\alpha}^{2}}\right]=-E \cdot\left[-\psi^{\prime}(\hat{\alpha})\right]= \\
& =\psi^{\prime}(\hat{\alpha}) \\
& W_{12}=-E\left[\frac{\partial^{2} \ln L\left(x_{1}, x_{2}, \ldots, x_{n} ; \hat{\alpha}, \hat{\beta}\right)}{\partial \hat{\alpha} \partial \hat{\beta}}\right]=-E\left[-\frac{1}{\hat{\beta}}\right]=\frac{1}{\hat{\beta}} \text {. } \\
& W_{12}=W_{2 i} \\
& W_{22}=-E\left[\frac{\partial^{2} \ln L\left(x_{1}, x_{2}, \ldots, x_{n} ; \bar{\alpha}, \bar{\beta}\right)}{\partial \hat{\beta}^{2}}\right]=-E\left[\frac{\hat{\alpha}}{\hat{\beta}^{2}}-\frac{2 \bar{x}}{\hat{\beta}^{3}}\right]=\frac{\hat{\alpha}}{\hat{\beta}^{2}}
\end{aligned}
$$




$$
\begin{aligned}
& W=\left[\begin{array}{rr}
\psi^{\prime}(\hat{\alpha}) & 1 / \hat{\beta} \\
1 / \hat{\beta} & \bar{\alpha} / \hat{\beta}^{2}
\end{array}\right], \text { para } \mathrm{n} \text { observações } \\
& W=n\left[\begin{array}{rr}
\psi^{\prime}(\hat{\alpha}) & 1 / \hat{\beta} \\
1 / \hat{\beta} & \hat{\alpha} / \hat{\beta}^{2}
\end{array}\right] \\
& \nabla=\frac{1}{n} W^{-1}
\end{aligned}
$$

Onde:

$$
\begin{aligned}
& W^{-1}=\frac{1}{\frac{1}{\beta^{2}}\left[\hat{\alpha} \psi^{\prime}(\hat{\alpha})-1\right]}\left[\begin{array}{lc}
\frac{\hat{\alpha}}{\hat{\beta}^{2}} & -\frac{1}{\hat{\beta}} \\
-\frac{1}{\hat{\beta}} & \psi^{\prime}(\hat{\alpha})
\end{array}\right] \\
& \nabla=\frac{1}{\eta\left[\hat{\alpha} \psi^{\prime}(\hat{\alpha})-1\right]}\left[\begin{array}{lc}
\hat{\alpha} & -\hat{\beta} \\
-\hat{\beta} & \beta^{2} \psi^{\prime}(\hat{\alpha})
\end{array}\right] \\
& \nabla(\hat{\alpha})=\frac{\hat{\alpha}}{\eta\left[\hat{\alpha} \psi^{i}(\hat{\alpha})-1\right]}, \nabla(\hat{\beta})=\frac{\beta^{2} \psi^{\prime}(\hat{\alpha})}{\eta\left[\hat{\alpha} \psi^{\prime}(\hat{\alpha})-1\right]} \\
& \operatorname{cov}(\hat{\alpha}, \hat{\beta})=\frac{-\hat{\beta}}{\eta\left[\hat{\alpha} \psi^{\prime}(\hat{\alpha})-1\right]}
\end{aligned}
$$

Conforme Nörlund, citado por THOM (1958).

$\psi^{\prime}(\tilde{\alpha})=\frac{1}{2}+\frac{1}{2 \hat{\alpha}^{2}}+\sum_{k=1}^{n} \frac{B_{2 k}}{\hat{\alpha}^{2 k+1}}+R^{\prime} m$

onde R.m é o resto após $m$ termos, avaliado pela inequação: $\left[R^{\prime} m\right]<\frac{B}{a^{2 m+3}}$

${ }^{1}$ NÖRLUND, N.E. Vorlesungen Uber Differenzenrechnung. Berlin, Springer, 1924. 
onde $B_{k}$ são os nümeros de Bernoulili.

Observa-se que quanto maior for a amostra menor será o intervalo de confiança, isto porque a variáncia das estimativas dos parâmetros é inversamente proporcional ao tamanho da amostra. Para amostras grandes um intervalo de confiança aproximado pode ser construido.

FRIEDMAN \& JANES (1957), acham que o nümero de observações da amostra deve ser maior que 30 , mas não fàzem pesquisa especial sobre o assunto. Considerando o nível de $90 \%$ de probabilidade, obtem-se os seguintes intervalos: $\alpha:$

$\hat{\alpha} \pm 1,64 \sqrt{\nabla(\hat{\alpha})}$

R:

$\hat{\beta} \pm 1,64 \sqrt{\bar{\nabla}(\hat{\beta})}$

Estes intervalos são construídos supondo que $\hat{\alpha}$ e $\hat{\beta}$ tenham distribuição aproximadamente normal, com média $\alpha$ e $\beta$ e variâncias $V(\bar{\alpha})$ e $V(\hat{\beta})$, respectivamente. MOOD \& GRAYBILL (1970), afirmaram que os parämetros que são desconhecidos, podem ser substituídos pelas estimativas, sem que isso afete consideravelmente o grau de aproximação.

3.2.4. Cälculo das estimativas das precipitações plu viais

Obtidos os estimadores $\hat{\alpha}$ e $\hat{\beta}$, pode-se determinar as estimativas de diferentes lâminas de ägua a um 
19.

determinado nivel de probabilidade conhecido ou de se estimar probabilidade atrâvés da distribuição acumulada, para verificar se a amostra retirada de uma população desconhecida, se ajusta à distribuição gama, utilizando a estatística $x^{2}$

De acordo com os elementos da amostra, duas situações podem ocorrer VIVALDI (1973).

a) A amostra não contēm valores nulos;

b) A mostra contém valores nulos.

Algumas considerações são feitas para os casos a e b.

Para o caso a, usa-se o modelo simples.

Modelo Simples

A distribuição acumulada è representada pela função gama incompleta:

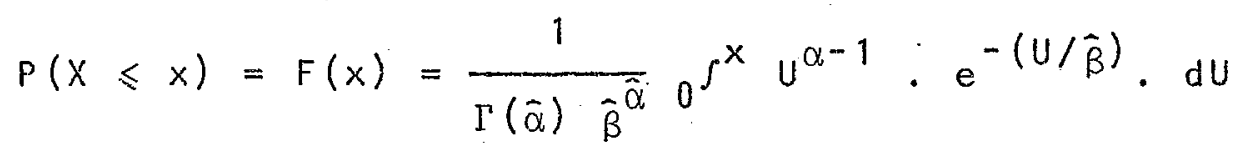

onde $x$ representa a precipitação pluvial. A antiderivada do integrando não é obtida de maneira imediata. Uma forma seria pelo método de simpson ou atravēs de desenvolvimento em série que será mostrado. Fazendo $T=U / \hat{\beta}$, $U=0 \Longrightarrow T=0, U=x \Longrightarrow T=x / \hat{\beta}, U=T \hat{\beta}, \quad d U=\hat{\beta} d T$ $F\left(\frac{x}{\hat{\beta}}\right)=\frac{1}{\Gamma(\hat{\alpha}) \hat{\beta}^{\hat{\alpha}}} \int^{x / \hat{\beta}} \cdot e^{-T} \cdot(T \hat{\beta})^{\hat{\alpha}-1} \cdot \hat{\beta} d T$ 


$$
\begin{aligned}
& F\left(\frac{x}{\hat{\beta}}\right)=\frac{1}{\Gamma(\hat{\alpha})} 0^{x / \hat{\beta}} e^{-T} \cdot T^{\alpha-1} d T \\
& F(t)=\frac{1}{\Gamma(\hat{\alpha})} 0^{t} e^{-T} \cdot T^{\alpha-1} d T,
\end{aligned}
$$

$$
\text { Com } t=\frac{x}{\hat{\beta}}
$$$$
e^{-T}=\sum_{n=0}^{\infty} \frac{(-1)^{n} T^{n}}{n !}
$$

$e^{-T}=1-T+\frac{T^{2}}{2 !}-\frac{T^{3}}{3 !}+\ldots+(-1)^{n} \frac{T}{n !}+R T$,

onde $\quad R(T)=(-1)^{n+1} \frac{T^{n+1}}{(n+1) !} e^{-\theta T}$.

$F(t)=\frac{1}{\Gamma(\hat{\alpha})} 0^{t}\left(T^{\alpha-1}-T^{\bar{\alpha}}+\frac{1}{2} T^{\hat{\alpha}+1}-\frac{1}{6} T^{\dot{\alpha}+2} \pm \ldots\right) d T$

$F(t)=\frac{t^{\bar{\alpha}}}{\Gamma(\hat{\alpha})}\left[\frac{i}{\hat{\alpha}}-\frac{t}{(\hat{\alpha}+1) 1 !}+\frac{t^{2}}{(\hat{\alpha}+2) 2 !}-\frac{t^{3}}{(\hat{\alpha}+3) 3 !} \pm \ldots\right]$

$$
\text { Multiplicando-se e dividindo-se por } e^{t} \text {, tem }
$$

-se:

$$
\begin{aligned}
F(t)= & \frac{t^{\hat{\alpha}}}{\hat{\alpha} \Gamma(\hat{\alpha}) e^{t}}\left[1+\frac{t}{(\hat{\alpha}+1)}+\frac{t^{2}}{(\hat{\alpha}+1)(\hat{\alpha}+2)}+\right. \\
& \left.+\frac{t^{3}}{(\hat{\alpha}+1)(\hat{\alpha}+2)(\hat{\alpha}+3)}+\cdots\right]
\end{aligned}
$$

A probabilidade de ocorréncia de um valor menor ou igual a $x$ è dada por $F(t)$, onde $t=x / \hat{\beta}$. 
Para determinar-se a precipitação pluvial $x$, conhecido o nível de probabilịdade, faz-se:

$$
\begin{aligned}
& F(t)=F \\
& \frac{t^{\hat{\alpha}}}{\hat{\alpha} \Gamma(\hat{\alpha}) e^{t}}\left[1+\frac{t}{(\hat{\alpha}+1)}+\frac{t^{2}}{(\hat{\alpha}+1)(\hat{\alpha}+2)}+\right. \\
& \left.+\frac{t^{3}}{(\hat{\alpha}+1)(\hat{\alpha}+2)(\hat{\alpha}+3)}+\cdots\right]-F=0 \\
& g\left(t_{i}\right)=\frac{t^{\hat{\alpha}}}{\hat{\alpha} \Gamma(\hat{\alpha}) e^{t}}\left[1+\frac{t}{(\hat{\alpha}+1)}+\frac{t^{2}}{(\hat{\alpha}+1)(\hat{\alpha}+1)}+\right. \\
& \left.=\frac{t^{3}}{(\hat{\alpha}+1)(\hat{\alpha}+2)(\hat{\alpha}+3)}+\cdots\right]-F=0
\end{aligned}
$$

Uma das maneiras de resolver está equação é atravēs da aplicação do algorítmo de Newton-Raphson:

$x_{n+1}=\dot{x}_{n}-\frac{f\left(x_{n}\right)}{f^{\prime}\left(x_{n}\right)}, \quad f^{\prime}\left(x_{n}\right) \neq 0$

Para o presente trabalho, tem-se

$$
t_{i+1}=t_{i}-\frac{g\left(t_{i}\right)}{g^{\prime}\left(t_{i}\right)}, \quad g^{\prime}\left(t_{i}\right) \neq 0
$$

$$
t_{i+1}=t_{i}-\frac{\frac{t_{i}^{\alpha}}{\hat{\alpha} \Gamma(\hat{\alpha}) e^{t_{i}}}\left[1+\frac{t_{i}}{(\hat{\alpha}+1)}+\frac{t_{i}{ }^{2}}{(\hat{\alpha}+1)(\hat{\alpha}+2)}+\frac{t_{i}{ }^{3}}{(\hat{\alpha}+1)(\hat{\alpha}+2)(\hat{\alpha}+3)}+\cdots\right]-F}{\frac{t_{i} \hat{\alpha}-1}{\Gamma(\hat{\alpha}) e^{t_{i}}}}
$$

E necessärio ter um valor inicial $\left(\mathrm{t}_{0}\right)$, para começar o processo, e esse valor depende de $\hat{\alpha}$ e F. THOM $(1968)$, pesquisando sobre esse valor concluiu que: 
Para $\hat{\alpha} \geqslant 1$

$$
\begin{aligned}
& t_{0}=\ln \frac{1}{1-F}+[1,51-2 F(1-F)](\hat{\alpha}-1), F \geqslant 0,50 \\
& t_{0}=\ln \frac{1}{1-F}+[0,49-2 f(1-F)](\bar{\alpha}-1), F<0,50
\end{aligned}
$$

Para $\hat{\alpha}<1$

$$
\begin{aligned}
& t_{0}=\frac{1,309 F}{\left(1-0,658 F^{2}\right)}-0,10,0,50<F<0,90 \\
& t_{0}=\frac{1,309 F}{\left(1-0,658 F^{2}\right)}-0,06 \quad F \geqslant 0,90 \\
& t_{0}=0,01 \quad F \leqslant 0,50 \\
& t_{1}=t_{0}-\frac{g\left(t_{0}\right)}{g^{\prime}\left(t_{0}\right)} \\
& t_{2}=t_{1}-\frac{g\left(t_{1}\right)}{g^{\prime}\left(t_{1}\right)}
\end{aligned}
$$

onde, $\xi=$ precisão desejada.

Encontrando o valor de $t$, que satisfaça a equação, isto ë, atingida. a convergência, tem-se: $x=t \hat{\beta}$ 


$$
x \text { = precipitação pluvial em } \mathrm{mm} \text {, estimada a }
$$

um nivel de probabilidade conhecido.

$$
\text { Para o caso b, usa-se o modelo misto. }
$$

Modeio Misto

Em periodos curtos é comum a não ocorrência de chuva. Então, THOM (1968) pesquisando sobre esse aspecto, introduziu o conceito de distribuição mista, e considerou a ocorrência de chuva como um fenômeno aleatörio com probabilidade $P$. a ocorrência, e probabilidade $Q$ a não ocorrência, sendo, $P+Q=1$.

A função de distribuição acumulado passa a ser:

$G(t)=Q+P F(t)$.

A estimativa de $Q$ é:

$\hat{\mathrm{Q}}=\frac{\mathrm{m}}{\mathrm{n}}, \quad$ onde

$m=$ nümero de zeros ém uma. sërie climatolögi-

ca;

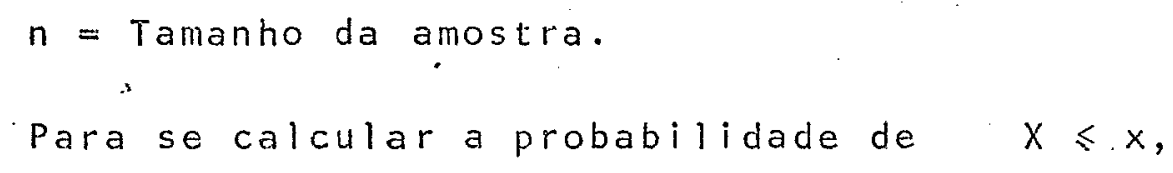

$H(t)=\bar{Q}+(1-\hat{Q}) F(t)-G=0$

Aplicando o processo de Newton-Raphson 


$$
\begin{aligned}
& t_{i+1}=t_{i}-\frac{H\left(t_{i}\right)}{H^{\prime}\left(t_{i}\right)}, \text { onde } \\
& H^{\prime}\left(t_{i}\right) \neq 0 ; \\
& x=t \bar{\beta} ; \\
& x=\text { precipitação pluvial māxima em mm, a um. }
\end{aligned}
$$

nivel de probabilidade conhecido.

$$
\text { Inicia-se o processo com um valor para t, }
$$

que varia com $\hat{\alpha}$ e $G$, obedecendo as mesmas fórmulas dé $(70),(71),(72),(73),(74)$. 


\section{RESULTADOS E DISCUSSAO}

\subsection{Resultados}

No Apēndice 1, nas Tabelas de 1 a 12 são encontrados os valores estimados e intervalos de confiança dos parâmetros $\alpha$ e $\beta$ referentes a 119 períodos. No Apêndice 2 , nas Tabelas de. 1 a 6 , são mostrados os resultados do teste de qui quadrado, entre a probabilidade esperada e observada para os 119 períodos estudados. No Apēndice 3, nas Tabelas de 1 a 12 são encontradas as quantidades de chuva associadas a 19. niveis de probabilidades para todos os perío dos.

\subsection{Discussão}

4.2.1. Estimativas de $\alpha$ e B.

Para a estimativa do parâmetro $\alpha$ observou- se que, de uma maneira geral, ao aumentar o tamanho do periodo cresceu o valor de. $\hat{\alpha}$, sendo menor a assimetria, mas houve casos, como março, onde no periodo de 1-18 a assime- 
tria foi maior do que no período de 1-15, setembro onde no periodo de 1-30 a assimetria foi maior do que no periodo de 1-27, novembro onde no período de 1-18, a assimetria foi maior que no período de 1-15 e dezembro onde no período de 1-18 a assimetria foi maior que no periodo de 1-15 como pode ser observado no Apêndice 1, Tabelas 3, 9, 11 e 12 respectivamente. Nos meses de maior ocorrencia de chuva os valores de $\hat{\alpha}$ foram em média, superiores aos obtidos nos meses menos chuvosos, como julho, agosto, setembro, outubro, novembro e dezembro. Sendo que os períodos desses meses apresentaram uma acentuada assimetria, o que explica os valores de $\hat{\alpha}$ inferiores.

0 período de menor assimetria foi $1-31$ no mês de janeiro, onde o valor de $\hat{\alpha}$ foi de 16,0954 e o periodo de maior assimetria foi de 1-3 no mês de dezembro, onde o valor de $\bar{\alpha}$ foi de 0,6863 como pode ser observado no Apếndice 1 , Tabelas 1 , e 12 respectivamente.

Para a estimativa do parâmetro $\beta$ observou-se que, de uma maneira geral, nos meses menos chuvosos os valores de $\hat{\beta}$ foram maiores. Este fato é explicado considerando que $\hat{\beta}$ varia em função de $\hat{\alpha}$ e da mëdia, e que nesses meses os valores $\hat{\alpha}$ são menores. A importância da estimativa do parâmetro $\beta$ está no câlculo da variância da amostra, uma vez que esta estimativa depende de $\hat{\beta}$ e $\hat{\alpha}$, en tão $\hat{\beta}$ é um indicador de variabilidade dos dados.

A precisão das estimativas dos parâmetros $\alpha$ 
e $\beta$ depende do valor de $\hat{Q}$, proporção de valores nulos da amostra. Quando $\hat{\mathrm{Q}}=0$, o tamanho da amostra foi de 34 , pois todos os dados da amostra foram utilizados na obtenção das estimativas, o que não ocorre quando $\hat{\mathbb{Q}}>0$. Neste caso - tamanho da amostra reduziu-se para $34(1$ - Q).

Nos periodos de $1-3$ dos meses de outubro e novembro, os valores de $\hat{Q}$ foram 0,2941 e 0,2647 , como pode ser observado no Apêndice 1 , nas Tabelas 10 e 11 respectivamente, nesses períodos somente 25 e 24 dados amostrais foram usados na obtenção das estimativas dos parâmetros. $\alpha$ e $\beta$. Devido o menor número de elementos amostrais as variancias de $\hat{\alpha}$ e $\hat{\beta}$ são maiores, pois essas são inversamente proporcionais ao tamanho da amostra, e os intervalos de confian ça também são afetados, porque da forma como foi feita a sua construção, é necessário que $\hat{\alpha}$ e $\widehat{\beta}$ tenham uma distribuição normal, isto só ocorre à medida que aumenta o tamanho da amostra.

Somente nos meses menos chuvosos e nos periodos 1-3, 1-6 e 1-9 os valores de $\hat{Q}$ foram diferentes de zero.

Os intervalos de confiança dos parâmetros $\alpha$ e $\beta$ foram construidos ao nivel de $90 \%$ de probabilidade. FRIEDMAN \& JANES (1957) acham que esse nivel è suficiente em se tratando de uma variável climatológica. Observou-se que, de uma maneira geral, os valores dos intervalos foram altos, mas a extremidade inferior nunca foi igual a zero, o que é um fato desejável, jä que $\alpha$ e $\beta$ são sempre maiores do que zero. 
As estimativas da assimetria e da variância dependem de $\hat{\alpha}$ e de $\hat{\alpha}$ e $\hat{\beta}$, respectivamente. A assimetria foi subestimada quando $\hat{\mathrm{Q}}>0$, porque os valores nulos não foram considerados. A variância quando $\hat{\mathrm{Q}}>0$, foi obtida a partir de $34(1-\hat{Q})$ dados amostrais, não representando a variabilidade dos dados em 34 anos.

\subsubsection{Teste de aderência}

Para verificar se os dados amostrais de cada período retirados de uma população de distribuição desconhecida, se ajus ta a distribuição gama, foi usado o teste $x^{2}$ com $v=k-1-m$ graus de liberdade, onde $k$ é o nümero de classes e $m$ è o número de parầmetros. 0 nível de significância foi de $5 \%$ de probabilidade.

De acordo com as Tabelas 4,5 e 6 (Apêndice 2), nos períodos de $1-3$ dos meses de agosto, outubro e novembro rejeitou-se a hipótese nula, esses meses são de baixa precipitação.

A precipitação pluviométrica para períodos pequenos dos referidos meses, apresenta uma irregularidade superior à apresentada pelos mesmos períodos dos meses chuvosos, o que proporciona uma divergência anormal nos cálculos de probabilidade. 


\subsubsection{Estimativas de diferentes alturas pluviais}

o emprego da distribuição gama na anālise dos dados pluviométricos, foi com o objetivo de se obter estimativas de quantidade de água em termos de probabilidade.

Observa-se na Tabela 5, Apêndice 3 , no período mensal do mês de maio hă $20 \%$ de probabilidade de chover quantidade igual ou inferior a $204,86 \mathrm{~mm}$. Isto indica que, dentro de 10 anos, em dois anos, espera-se no mês de maio uma precipitação igual ou menor do que $204 ., 86 \mathrm{~mm}$ ou alternativamente, em oito anos dentro de 10 anos, espera-se que em maio a precipitação exceda a $204,86 \mathrm{~mm}$. No mesmo periodo.ao nivel de $60 \%$ corresponde a $278,68 \mathrm{~mm}$ indicando que em seis anos dentro de 10 anos, a precipitação esperada será igual ou inferior a $278,68 \mathrm{~mm}$ ou em 4 anos, dentro de 10 anos espera-se mais do que $278,68 \mathrm{~mm}$. Este raciocinio pode ser expandido para todos os períodos dos demais meses.

- Inferencias estatisticas pode-se fazer usando as variancias dos dados para comparação das diferenças entre as precipitações esperadas entre umá alta e baixá probabili dade. No período mensal de março a amplitude entre $5 \%$ e $95 \%$ é de 330,44 para o período mensal de agosto, a variação entre os mesmos níveis è de 161,20 , as variancias 110,6762 e 24,8866, respectivamente: Desta maneira, num certo espaço de tempo, uma precipitação maior pode ser geralmente esperada em março, com relação a agosto, porēm, a precipitação em 
março provavelmente será mais irregular do que a de agosto, em virtude das variancias. 


\section{CONCLUSOES}

A partir das anälises efetuadas no presente trabalho, obtem-se as seguintes conclusões:

1. 0 métodos da māxima verossimelhança foi eficiente na estimação dos parâmetros $\alpha$ e $\beta$.

2. A hipötese nula não foi rejeitada em $97,48 \%$ dos períodos estudados, o que comprova a eficácia da distribuição gama incompleta para a estimativa de quantidades de chuva, para o municipio de Belëm-PA.

3. O algoritmo de Newton-Raphson foi eficiente, na solução da equação usada, para estimar precipitação pluvial a um certo nivel de probabilidade, porque houve a convergência do mētodo.

4. No período de 1-3 dos meses de baixa precipitação; como agosto, outubro e novembro, as freqüências esperadas não estão de acordo com as observadas. Esta discrepância foi causada pela redução do tamanho da amostra. Nesse período a distribuição gama incompleta não apresentou bons resultados párá a anälise dos dados de chuva. 


\section{REFERENCIAS BIBLIOGRAFICAS}

AMARAL, L.E. Anālise Harmônica. Pesquisa Agropecuāria Brasi leira. $3: 7-43,1968$.

AMARAL, L.E. E SILVA, J.B. Tabelas de probabilidades das precipitações pluviomētricas em Pelotas, RS, 1970.27 p. ARRUDA, V.H. E PINTO, H.S. A simplified gamma i probability model for analysis of the frequency distribution of rainfali in the region of Campinas. Sp, Brazil. Agricultural meteoroly, 22:101-8, 1980.

BARGER, G.L. E THOM, H.C.S. Evaluation of drought hazard. (Z) Agronomy dournal, $41(11): 519-26,1949$.

BARGER, G.L.; SHAW, R.H. E DALE, R.F. Gamma distribution parameters from 2 and 3 week precipitation tocals in the Morth Central region of the United States. lowa State University. Agricultural and Home Economics Experiment Station. 1959. $183 \mathrm{p}$.

ELLIS, J.Anälise estatistica das alturas de chuva anuais e mensais em Manaus, Amazonas. Departamento Nacional : de Meteorologia. M.A. Boletim. Técnico, 7:1-12, 1972. 
FRIEDMAN, D.G. E JANES, B.E. Estimation of rainfall probabilities. University of Connecticut Agricultural Experiment Station, Bulletin, 332:1-22. 1957.

HARDEE, J.E. Analysis of colombian precipitation to estimate irrigation requeriments. Utah wtaer Research Laboratory publication. 1971. $67 \mathrm{p}$.

HOFFMANN, R. E VIEIRA, S. Variância e corariância das estimativas dos parāmetros. In: HOFFMANN, R. E VIEIRA, S. A nâli se de regressão: uma introdução à econometria. São Paulo, Hucitec-EDUSP, 1977. cap. 2, p. 49-58.

MILNE, W.E. Càlculo numérico. São Paulo. Polígono. 1968. 346 p.

PORTO, E.R.; HANCOCK, J.K. E BARROS, L.C.G. Anälise das estimativas de chuva, para Santana do Ipanema e Palmeiras das Indias, AL, através da distribuição gama e da média. In : CONGRESSO BRASILEIRO DE ENGENHARIA AGRICOLA, , 9, Campina Grande-PB, 1979. Anais. Campina Grande-PB. UNI VERSIDADE FEDERAL DA PARATBA, 1980. v. 2, p. 52-7.

STROMMEN, N.D. E HORSFIELD, J.E. Monthly precipitation probabilities by'Climatic Divisions. Departamento de Agricultura dos Estados Unidos. 1969. 140 p.

THOM, H.C.S. A note on the gamma distribution. Monthly 10 weather review, 86(4):117-22, 1958.

THOM, H.C.S. Some methods of climatological analysis. Who, Geneva, 1966. 53 p. (Technical Note, 81): 
THOM, H.C.S. Direct and inverse tables of the gamma distribution. Environmental Data Service. Departamento do Comércio dos Estados Unidos. 1968. $30 \mathrm{p}$.

VIVALDI, L.d. Utilização da distribuição gama em dados pluviométricos. Piracicaba, 1973. 77 p. (Mestrado - Escola Superior de Agricultura "Luiz de Queiroz"/USP).

WEAVER, C.R. E MILLER, M. A precipitation probability computer program. Ohio. Agricultural research and Development Center. 1967. $10 \mathrm{p}$. 


\section{BIBLIOGRAFIA RECOMENDADA.}

ALBRECHT, P. Anālise numērica; um curso moderno. Rio de Janeiro, Livros Técnicos e Científicos, 1973. 252 p. ANDERSON, T.W. The statistical analysis of time series. New York, John Wiley and Sons, 1971. 704 p.

BARTHOLOMEW, D.J. Testing of depature from the exponential distribution. Biometrika, 44:253-7, 1957 .

CAMPOS, H. Testes aplicāveis a uma amostra. In: CAMPOS, H. Estatistica experimental não paramétrica. 3? ed. Piracicaba-SP, 1979. cap. 2, p. 21-62.

CHAPMAN, D.G. Estimating the parameters of a truncaded gamma distribution. Annal of Mathematical Statistics 27: $498-506,1956$

CHOI, S.C. E WETTE, R. Maximum likelihood estimation of parameters of the gamma distribution an their bias. Technometrics, $11(4): 683-90,1969$.

GOMES, P.F. A distribuição de qui-quadrado. In: GOMES, P.F. Iniciação à estatística. 6? ed. Piracicaba, SP, Nobe1, 1978. cap. 9, p. 151-65. 
HOFFMANN, R. O teste de qui-quadrado. In: HOFFMANN, R. Es tatística para economistas. São Paulo, Pioneira, 1980, cap. 13, p. 197-210.

MIRShaWKa, A.V. Cálculo Numérico. São Paulo, Nobel, 1979. $601 \mathrm{p}$.

PEARSON, E.S. \& HARTLEY, H. Biometrika tables for statisticians. London, The syndics of the Cambridge, 1956. $238 \mathrm{p}$. 


\section{APÉNDICE 1}

ESTIMATIVAS DE $\alpha, \beta, \theta$, ASSiMETRIA $\left(a_{3}\right)$, MËDIA E VARIÂNCIA DAS PRECIPITAÇÕES OBSERVADAS $\left(\hat{\mathrm{m}}, \mathrm{s}^{2}\right)$, DES VIO PADRÃO DE $\hat{\alpha}$, DESVIO PADRÃO DE $\hat{\beta}$ E INTERVALOS DE CONFIANÇA DOS PARÁMETROS $\alpha, \beta$, OBTIDOS EM TODOS OS PERĨODOS ESTUDADOS 
38.

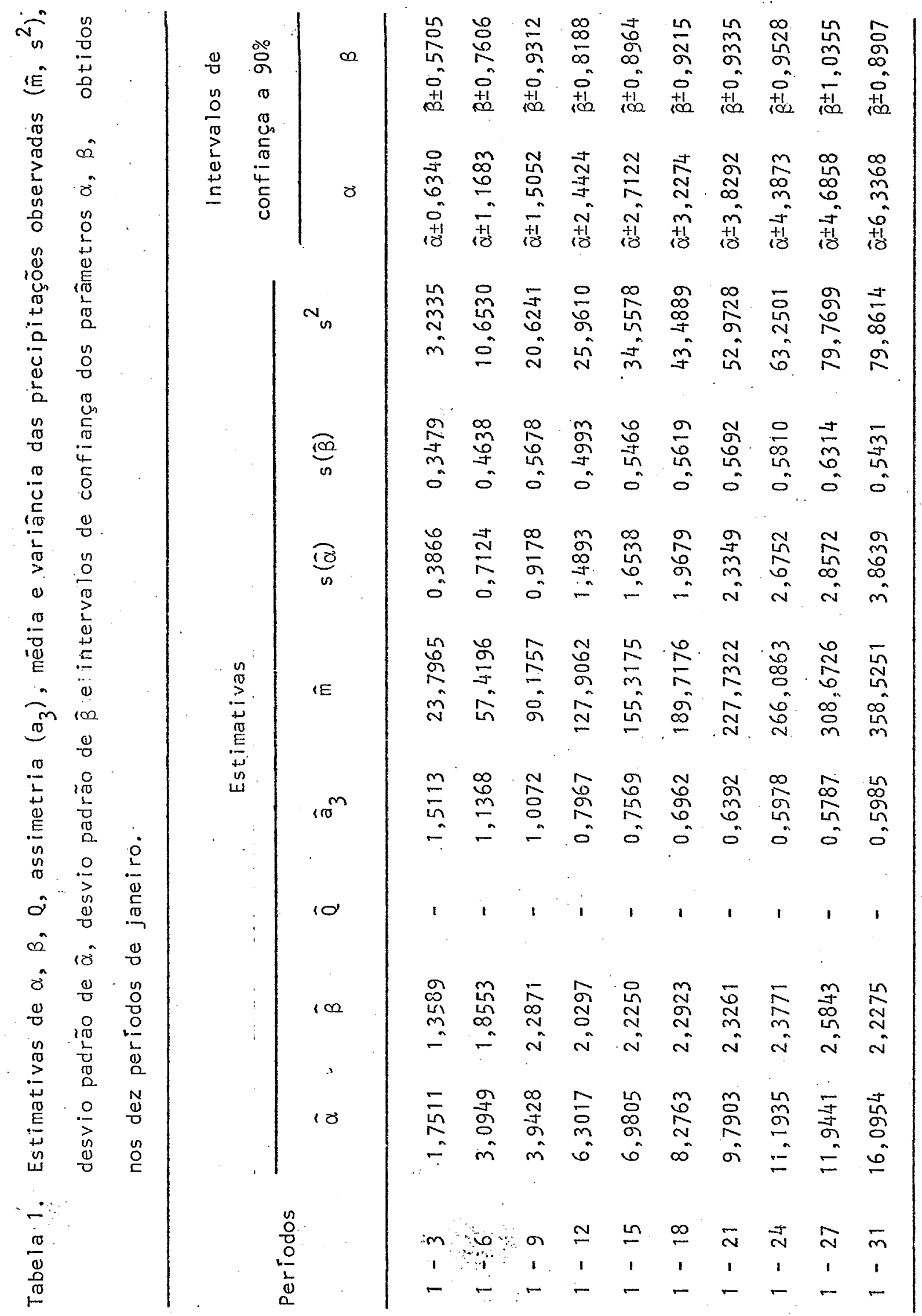


39.

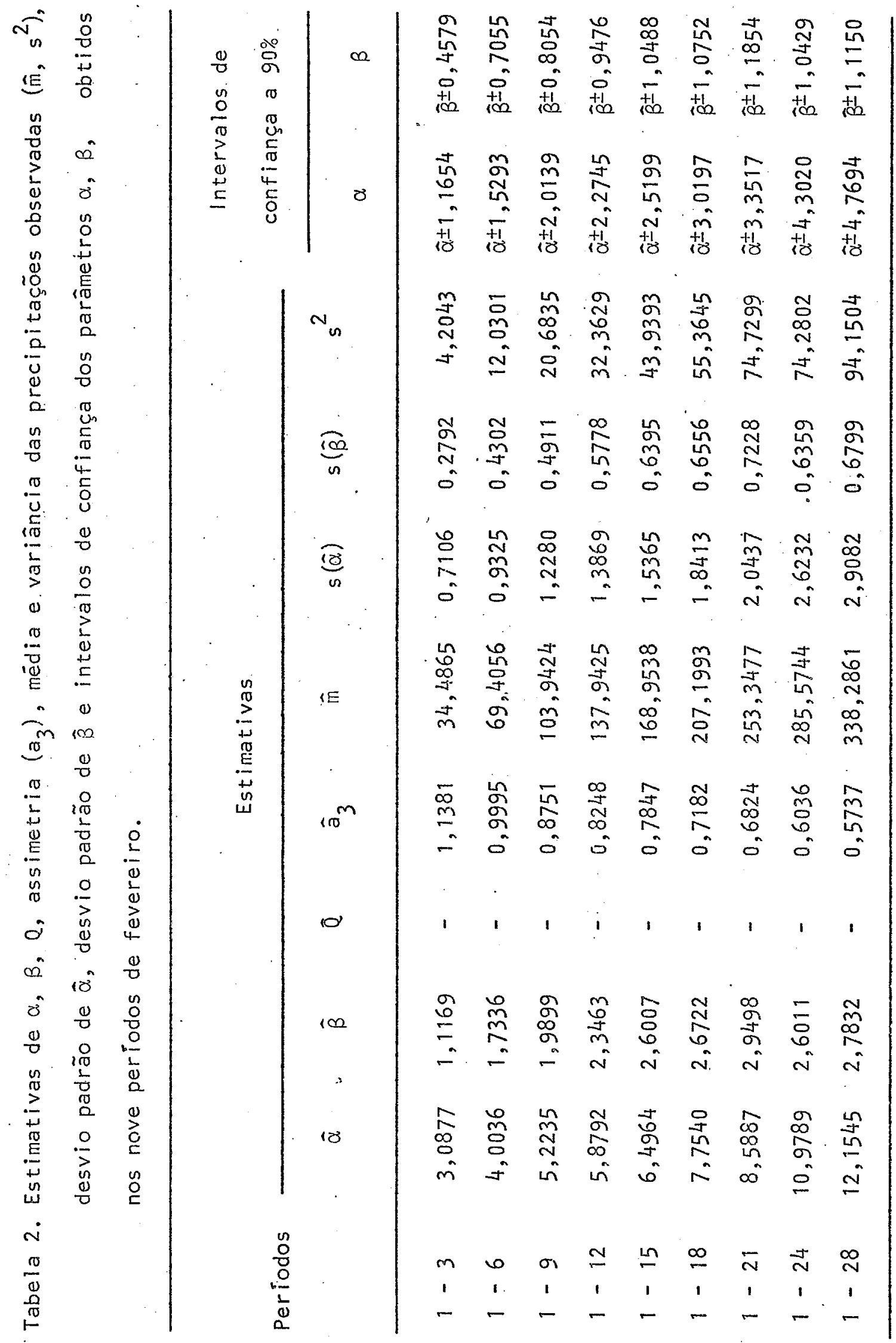




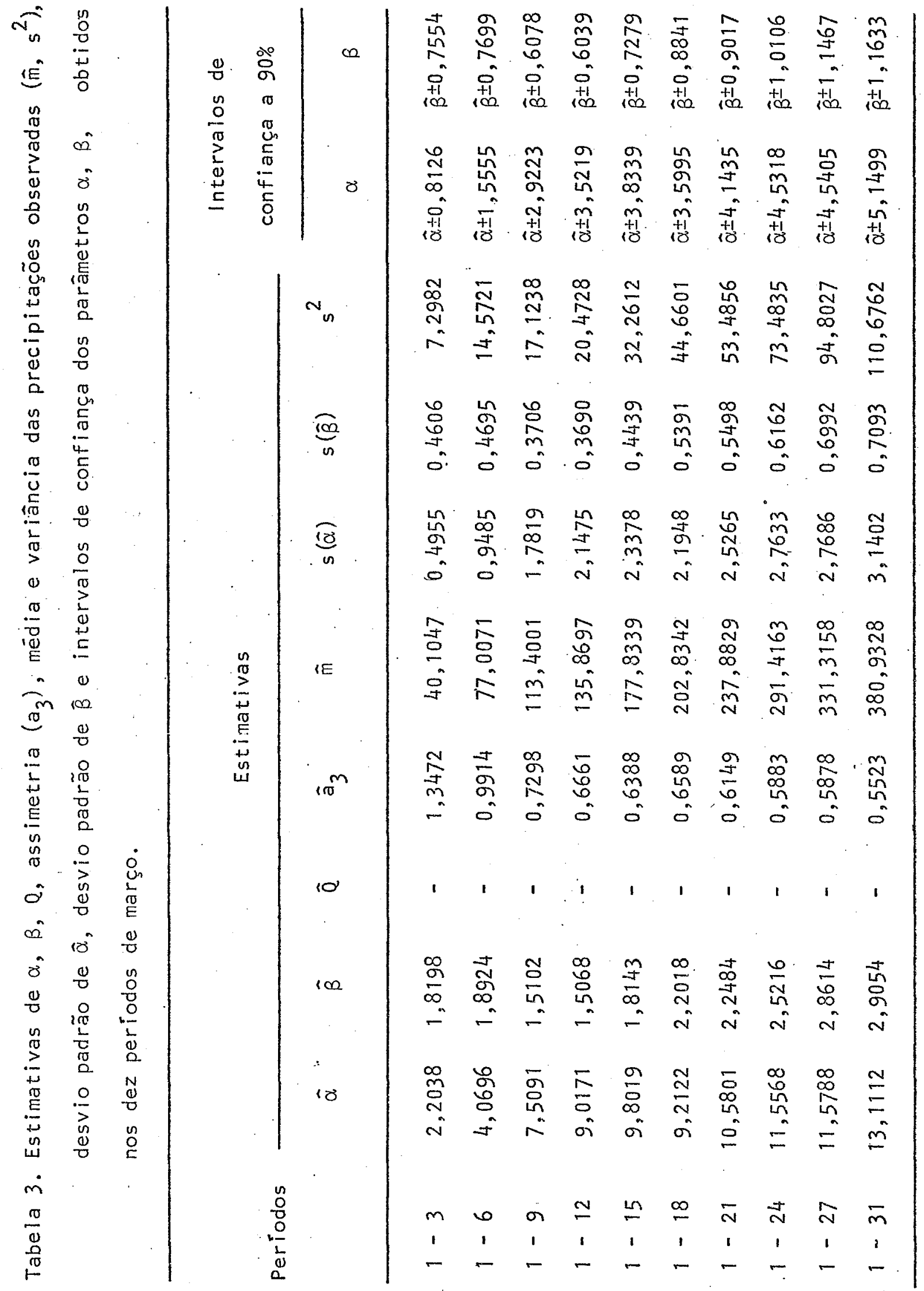


41.

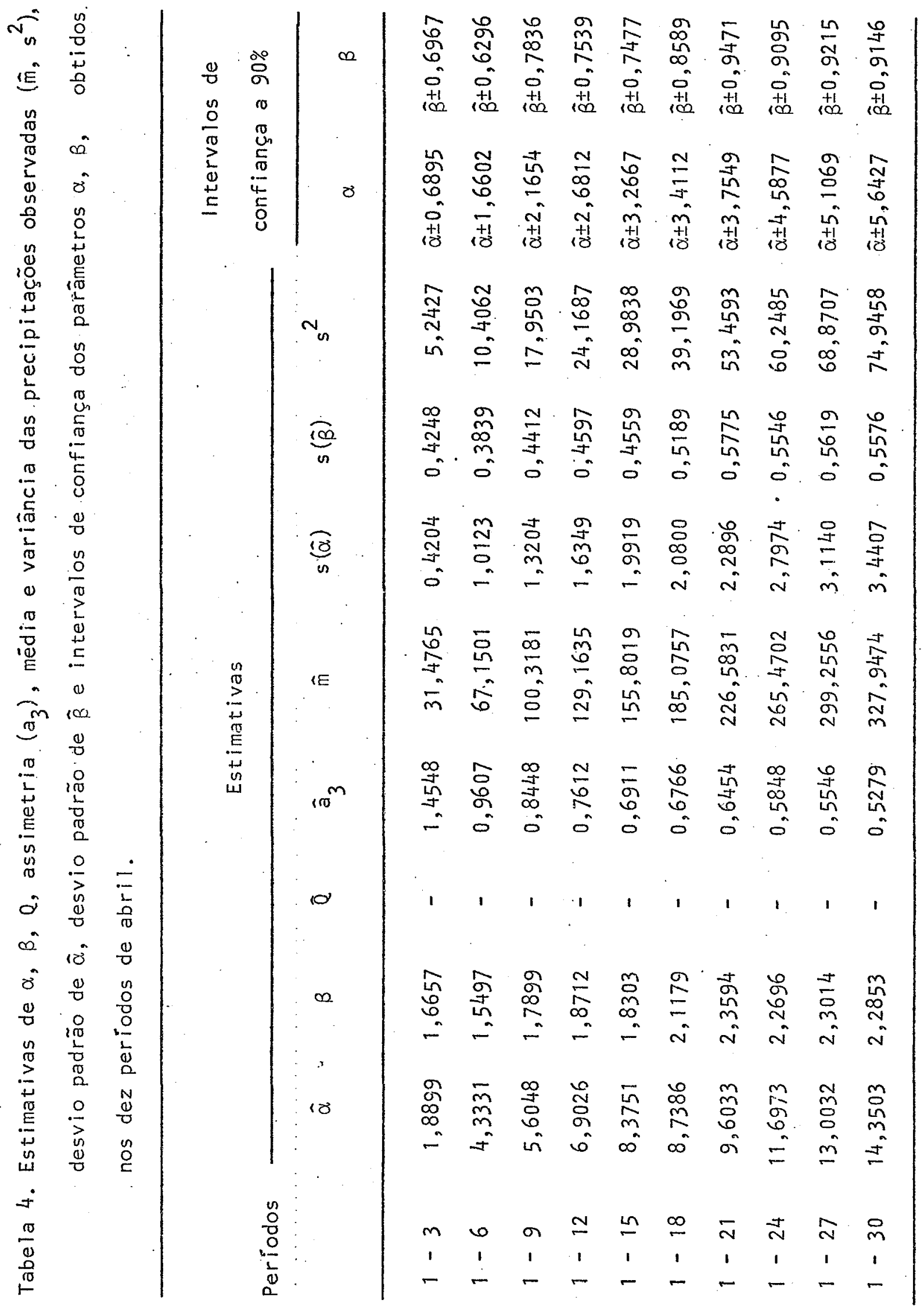


42.

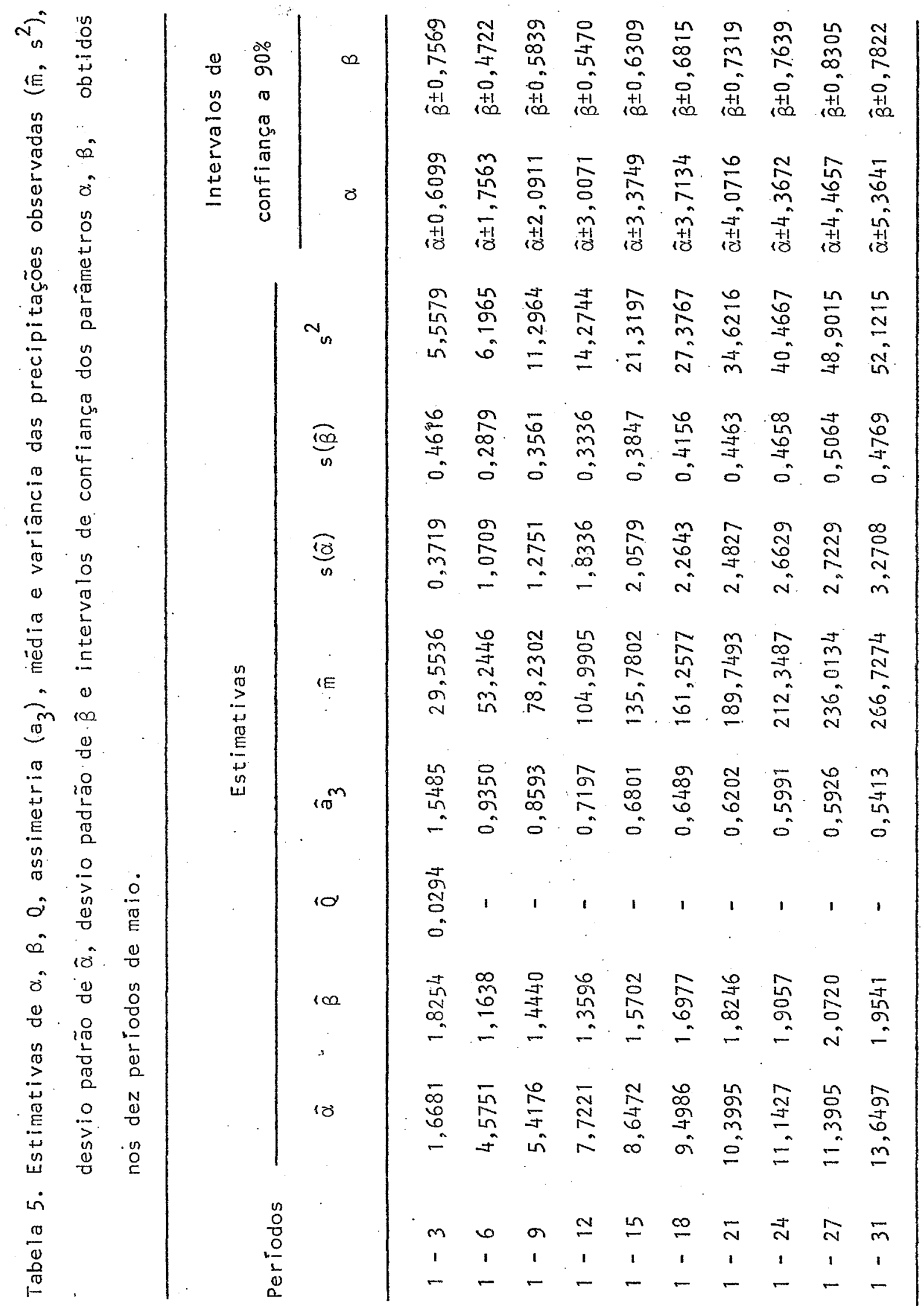


43.

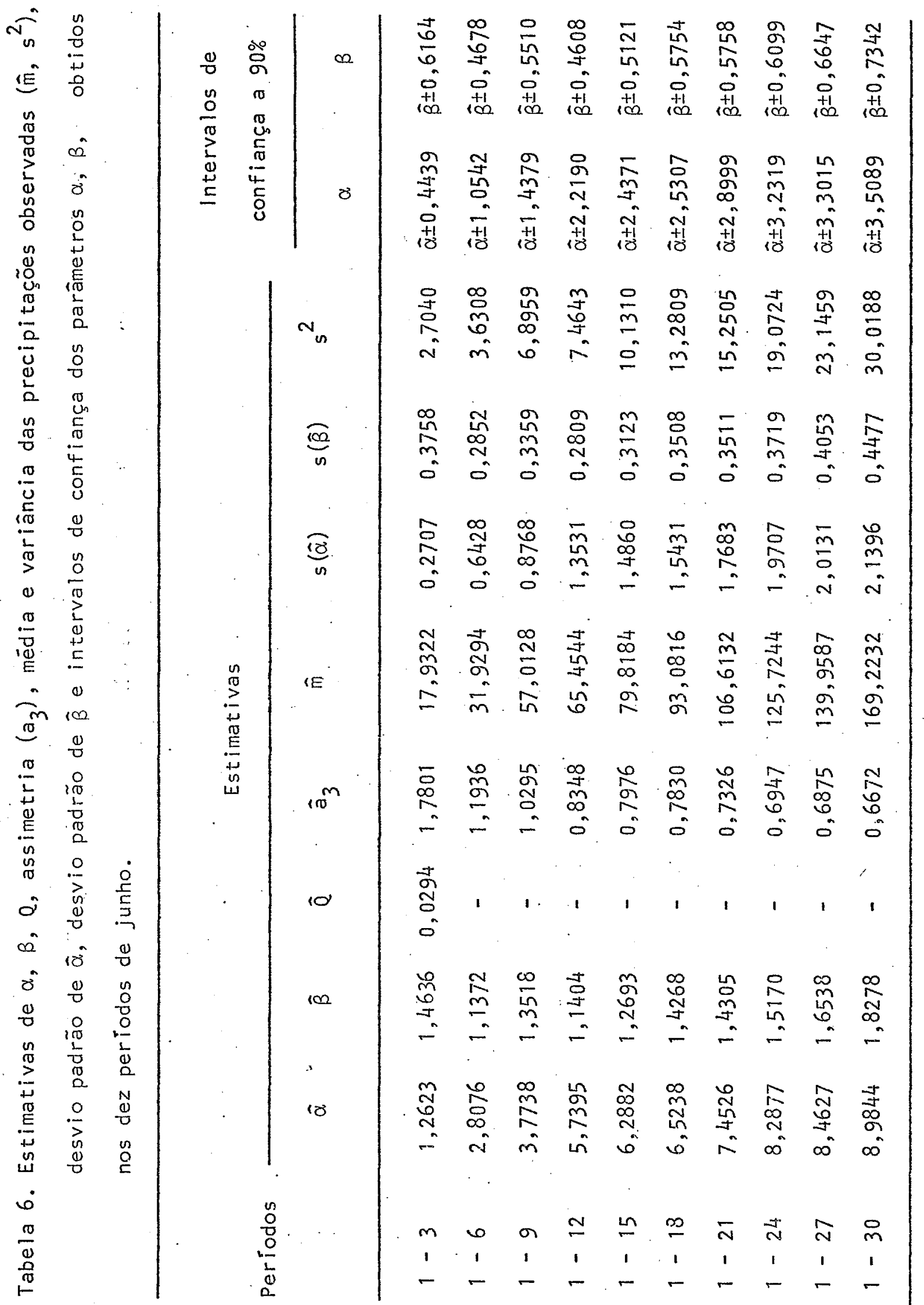


44.

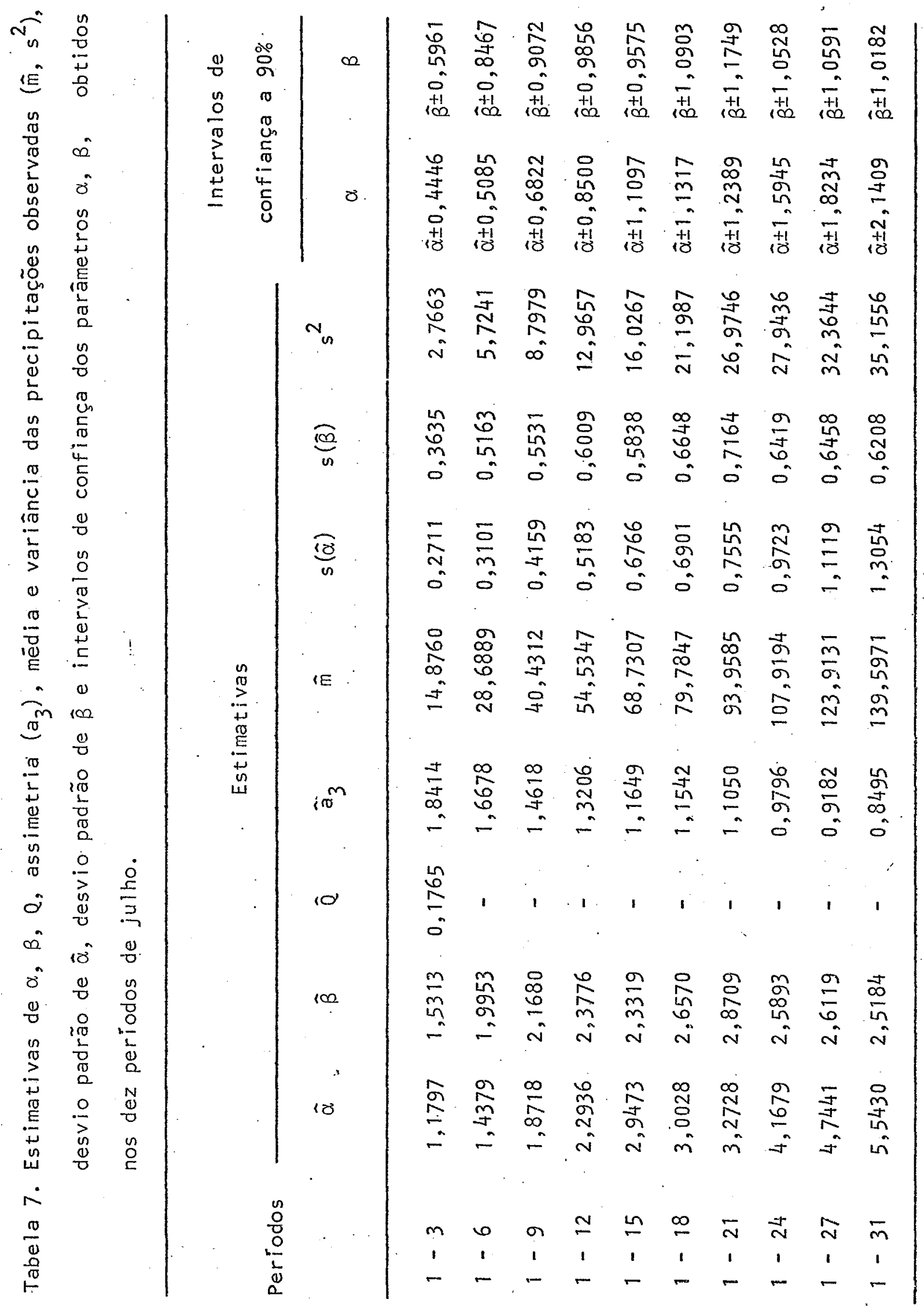


45.

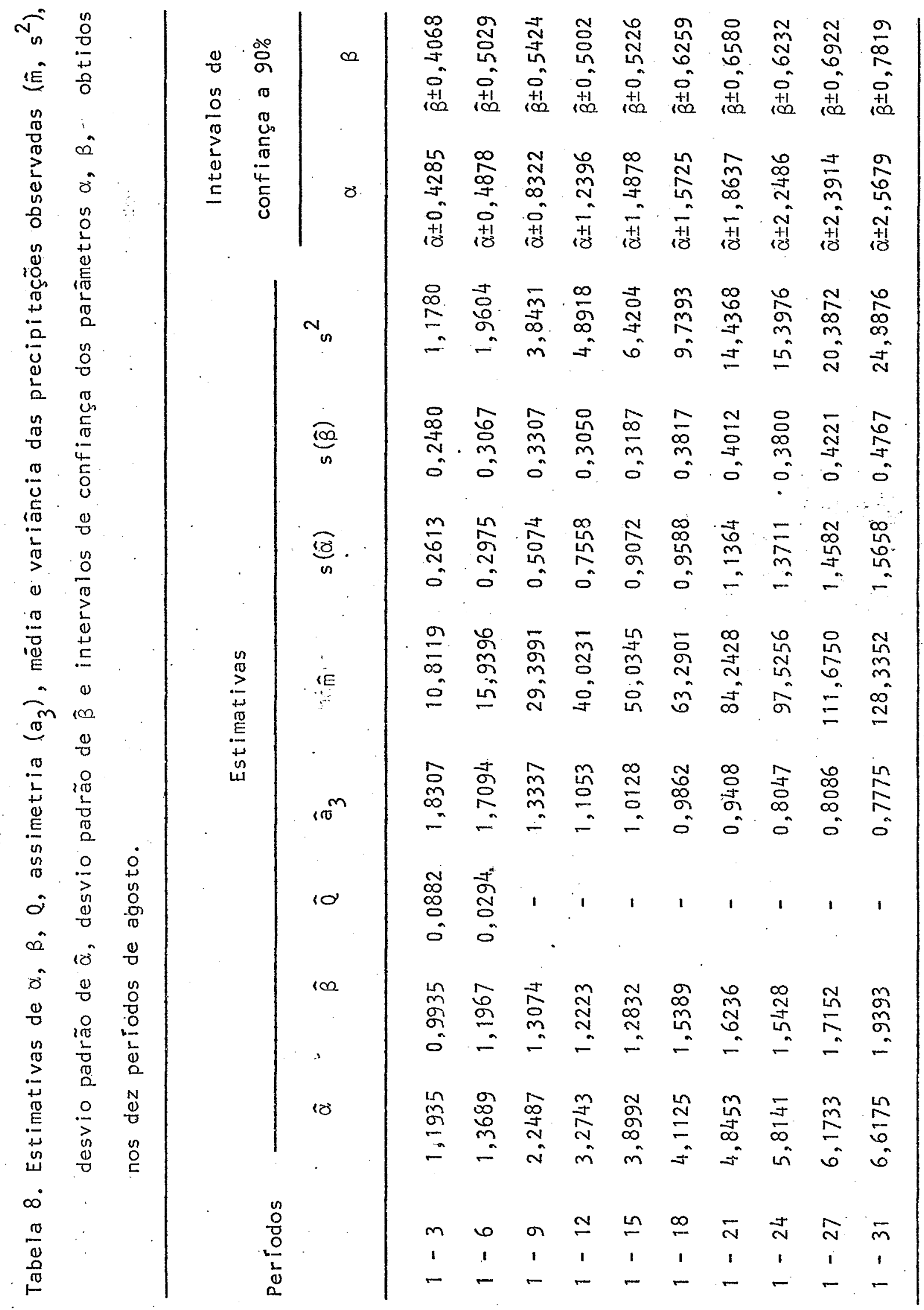


46.

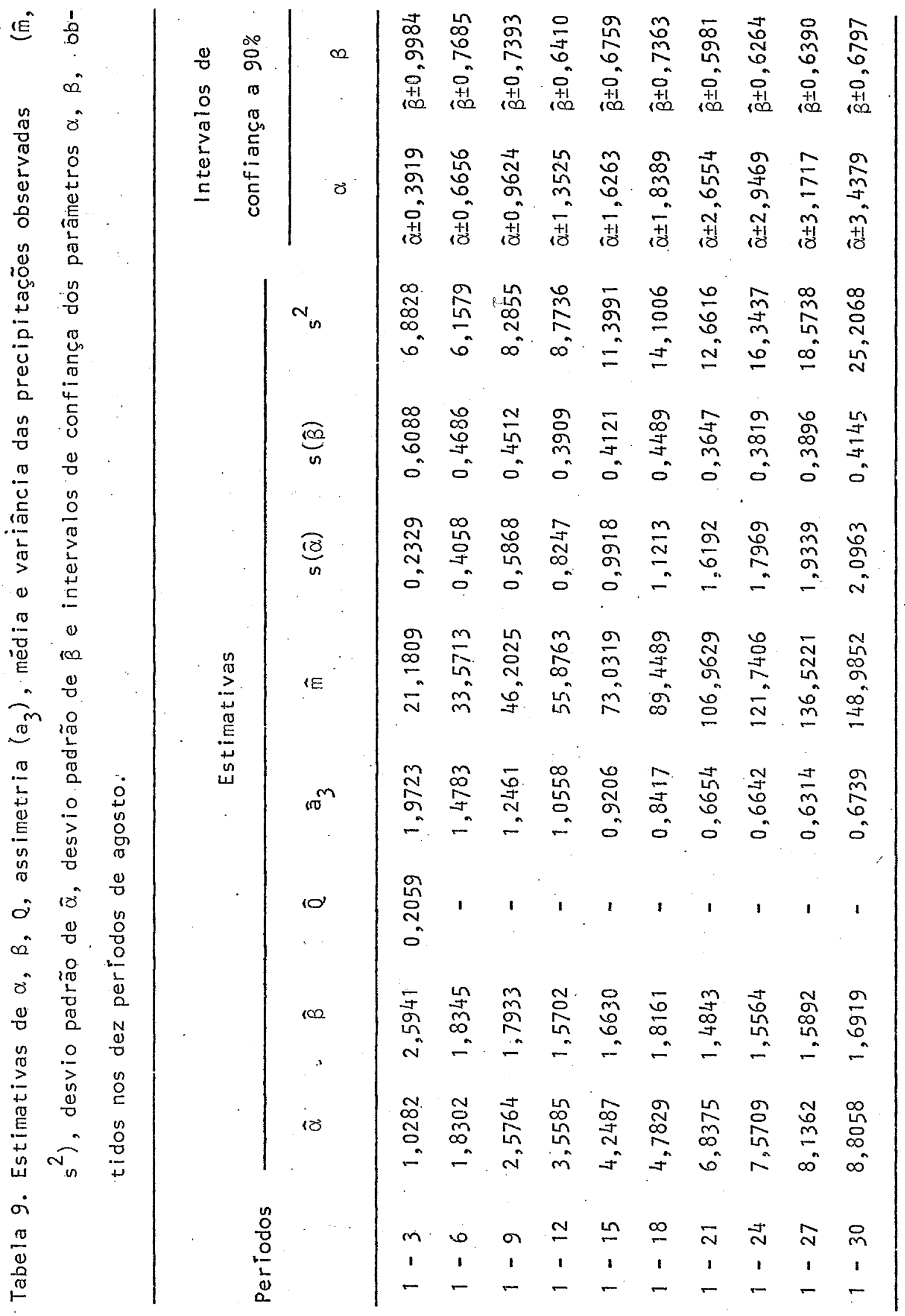




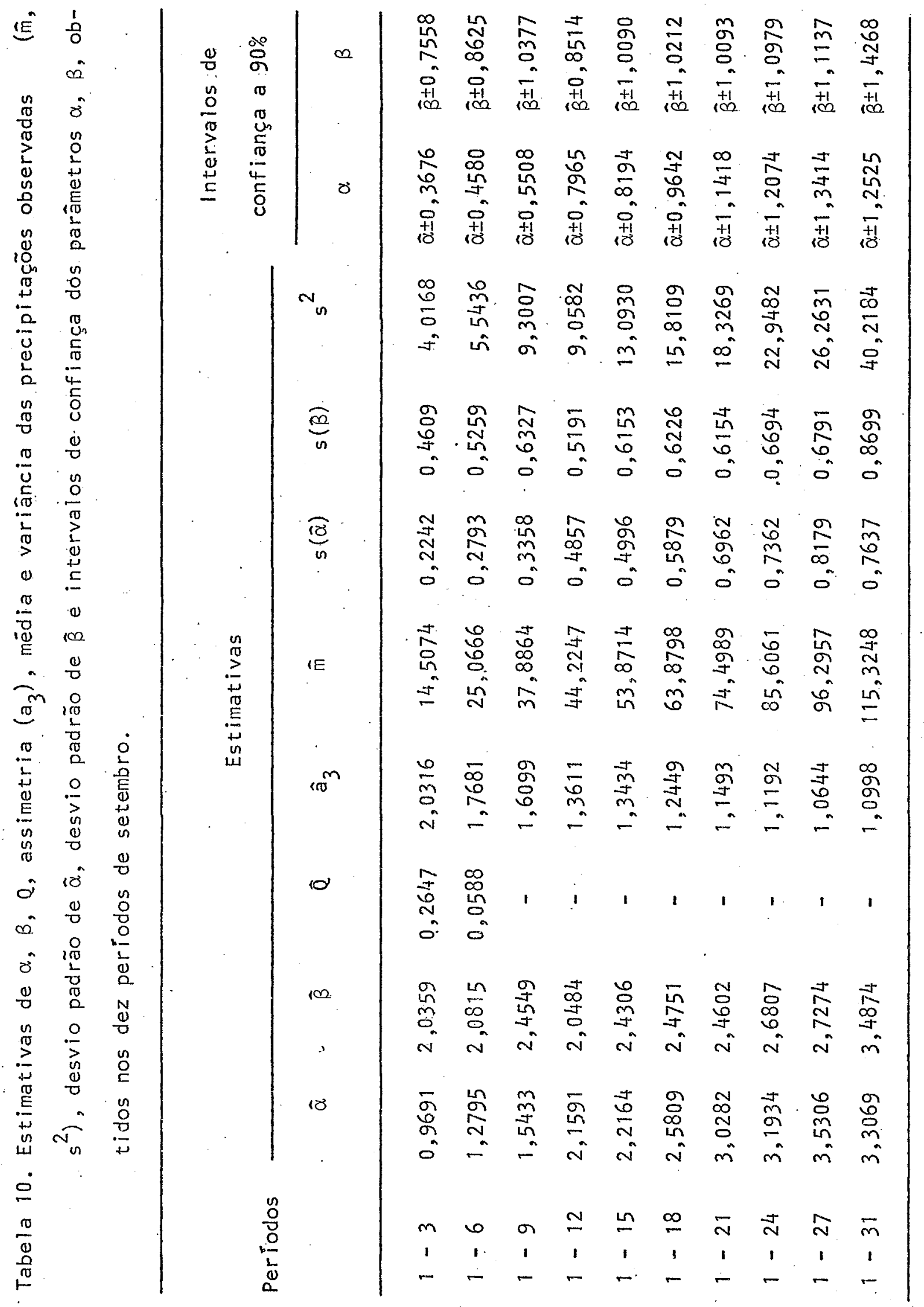


48.

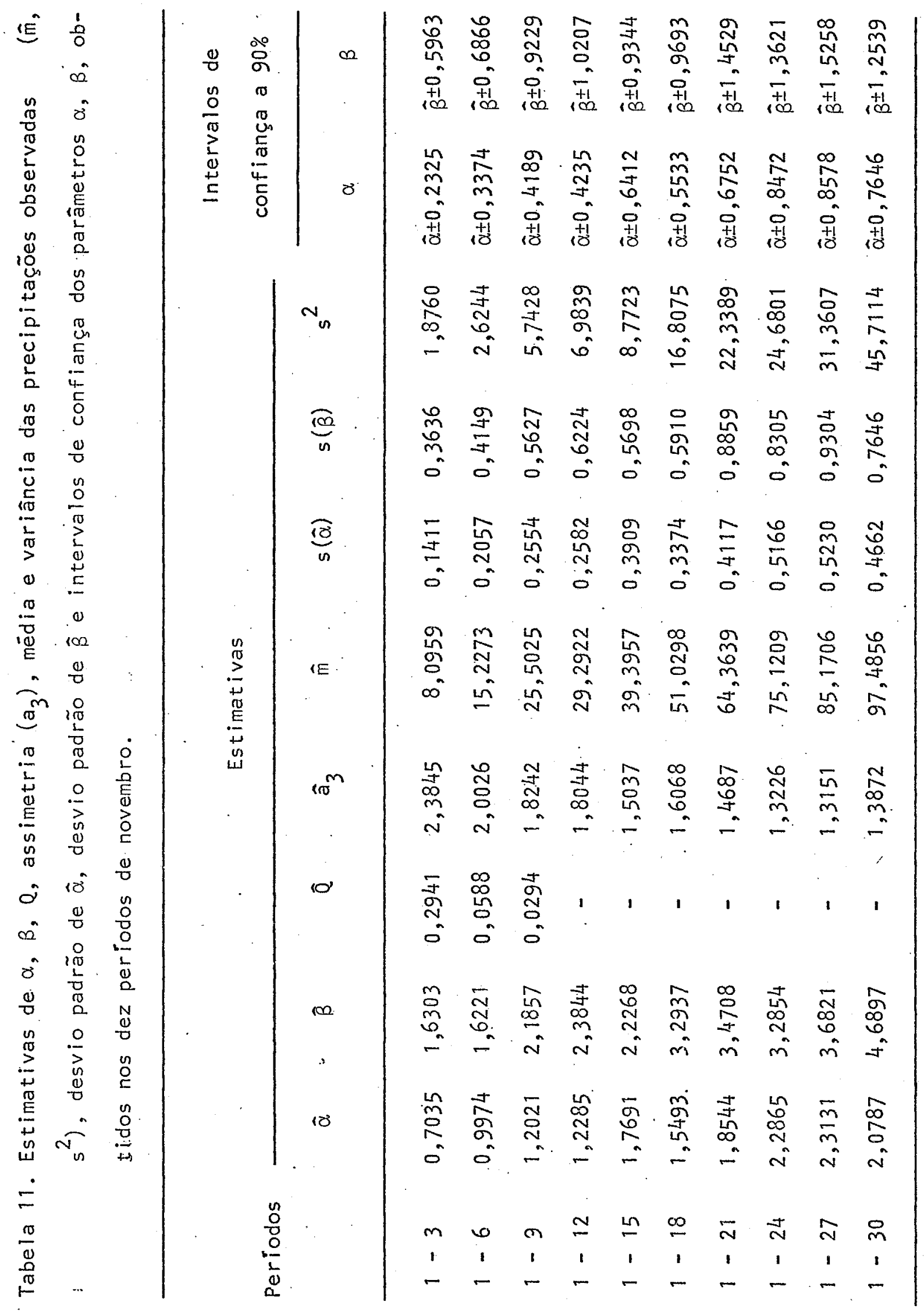


50.

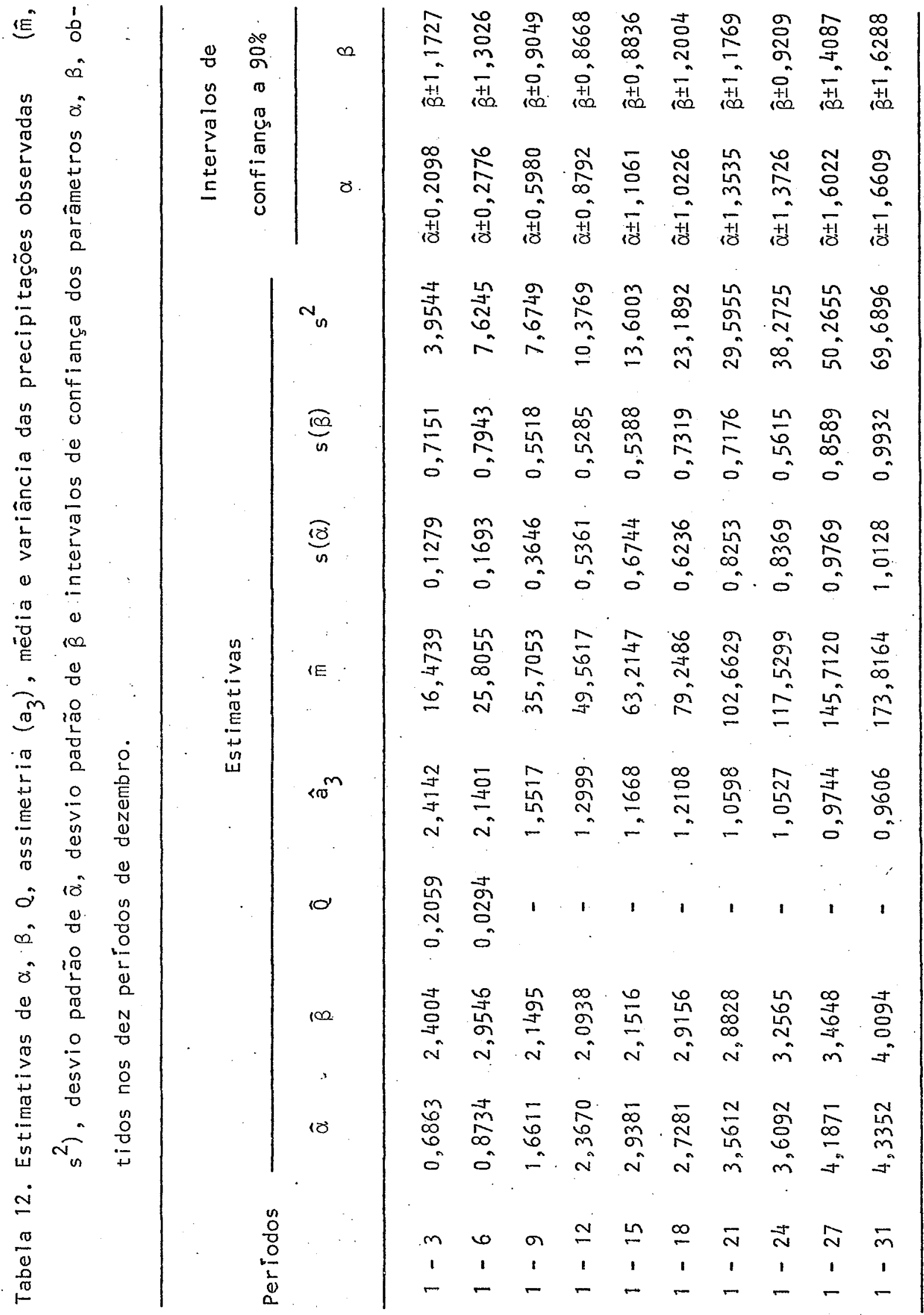


APÊNDICE 2

VALORES DE $x^{2}$ OBTIDOS NO TESTES DE AJUSTAMENTO

PARA TODOS OS PERIODOS ESTUDADOS 


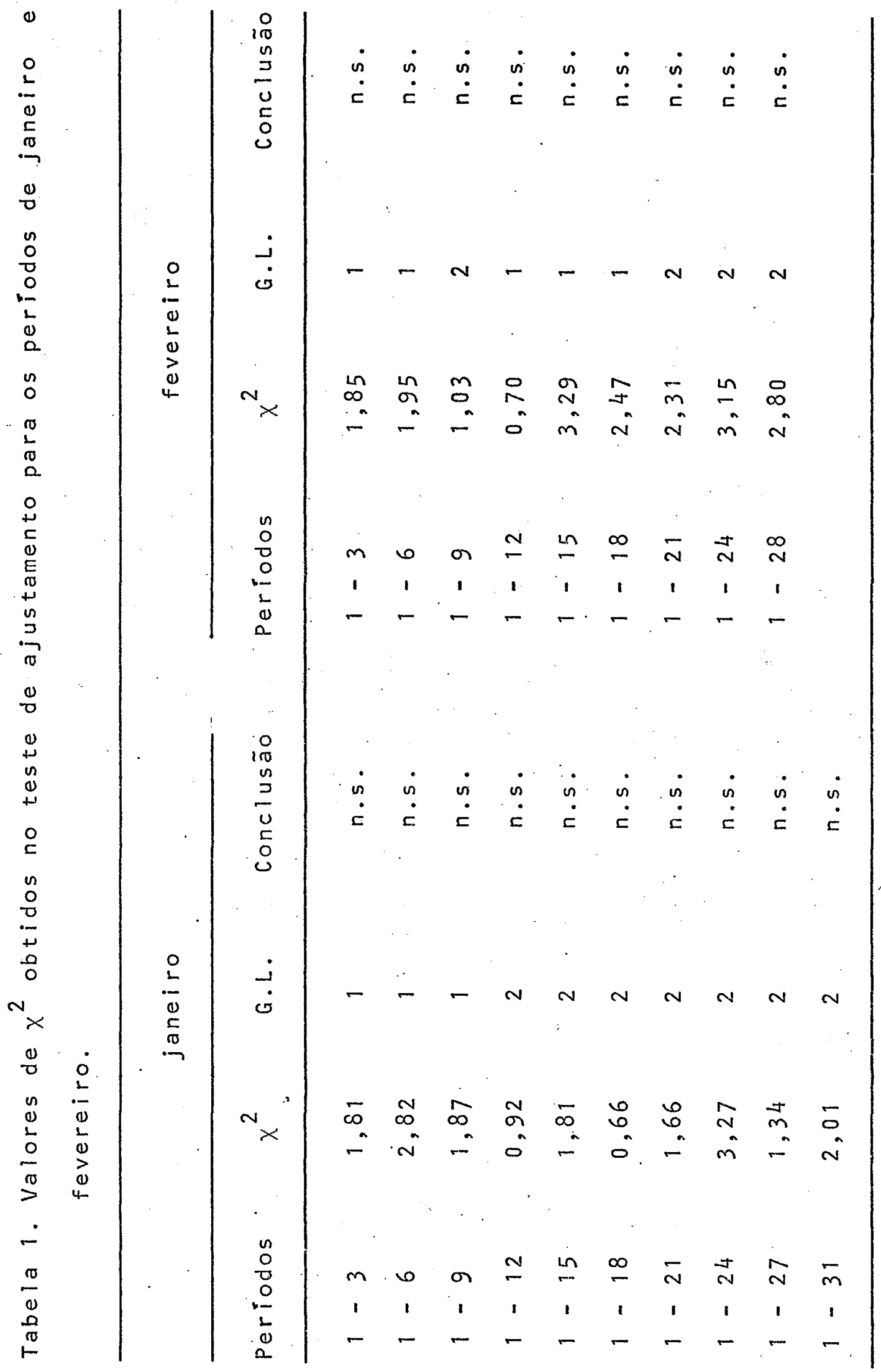


53.

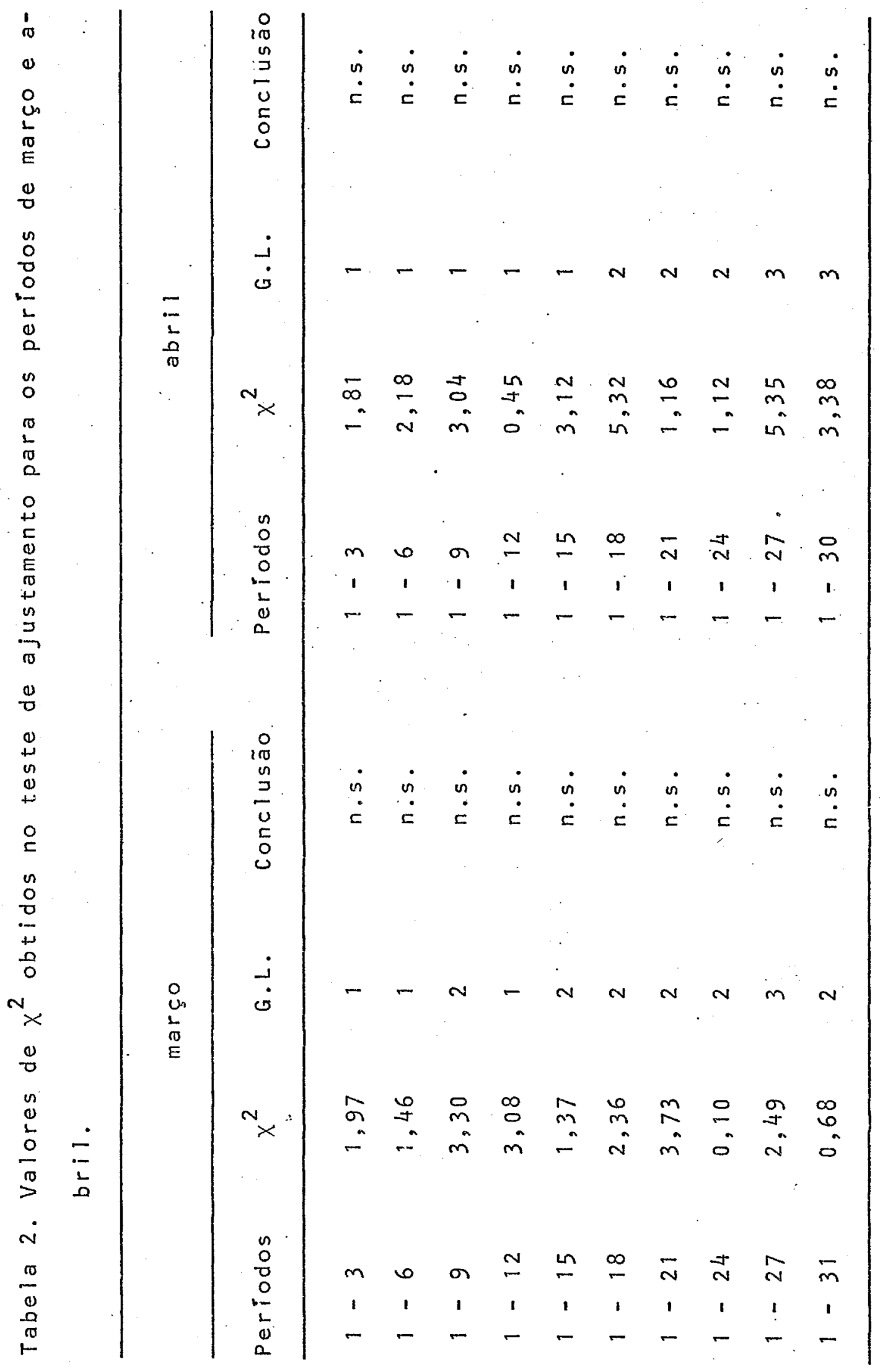


54.

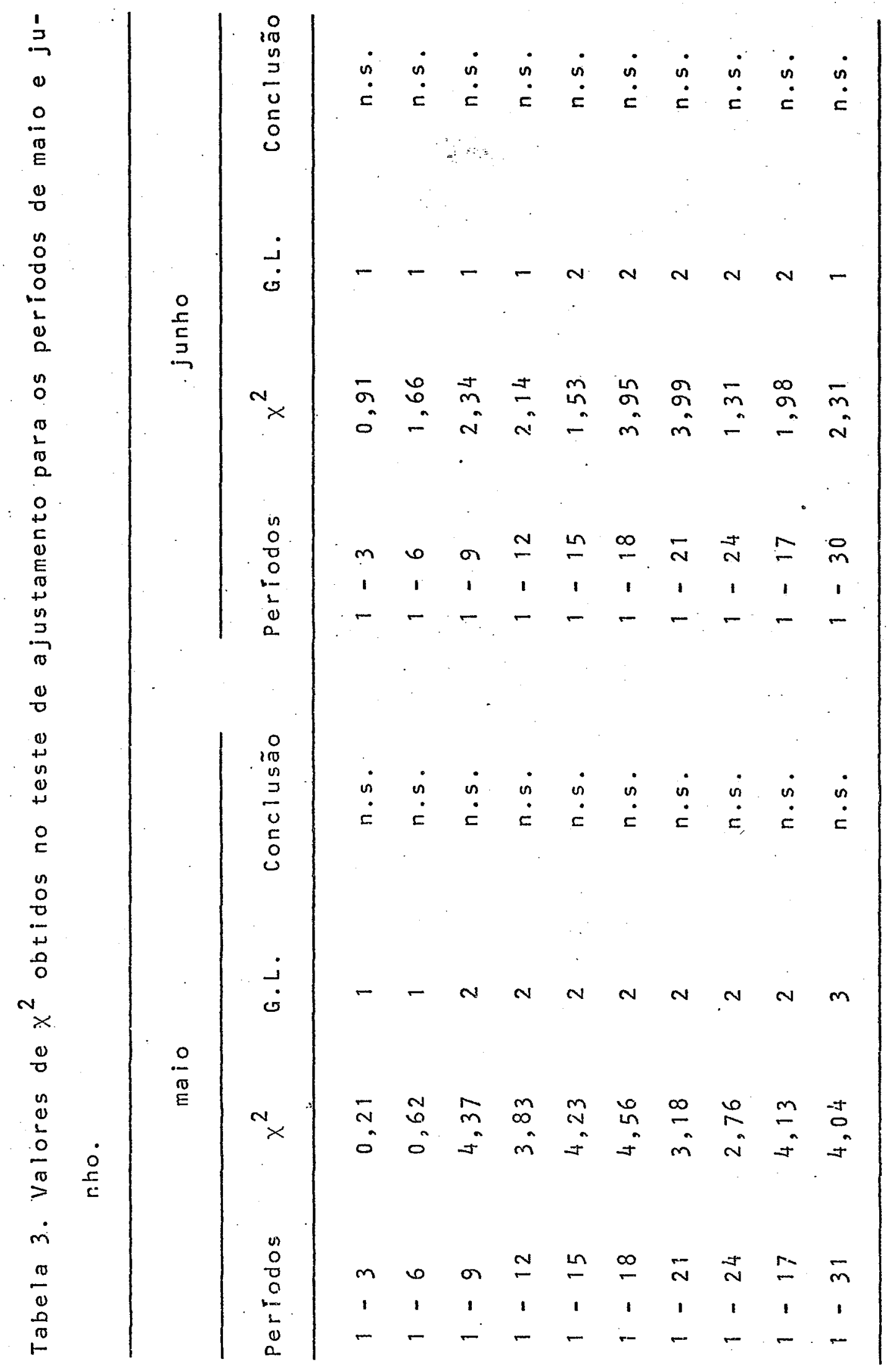


55.

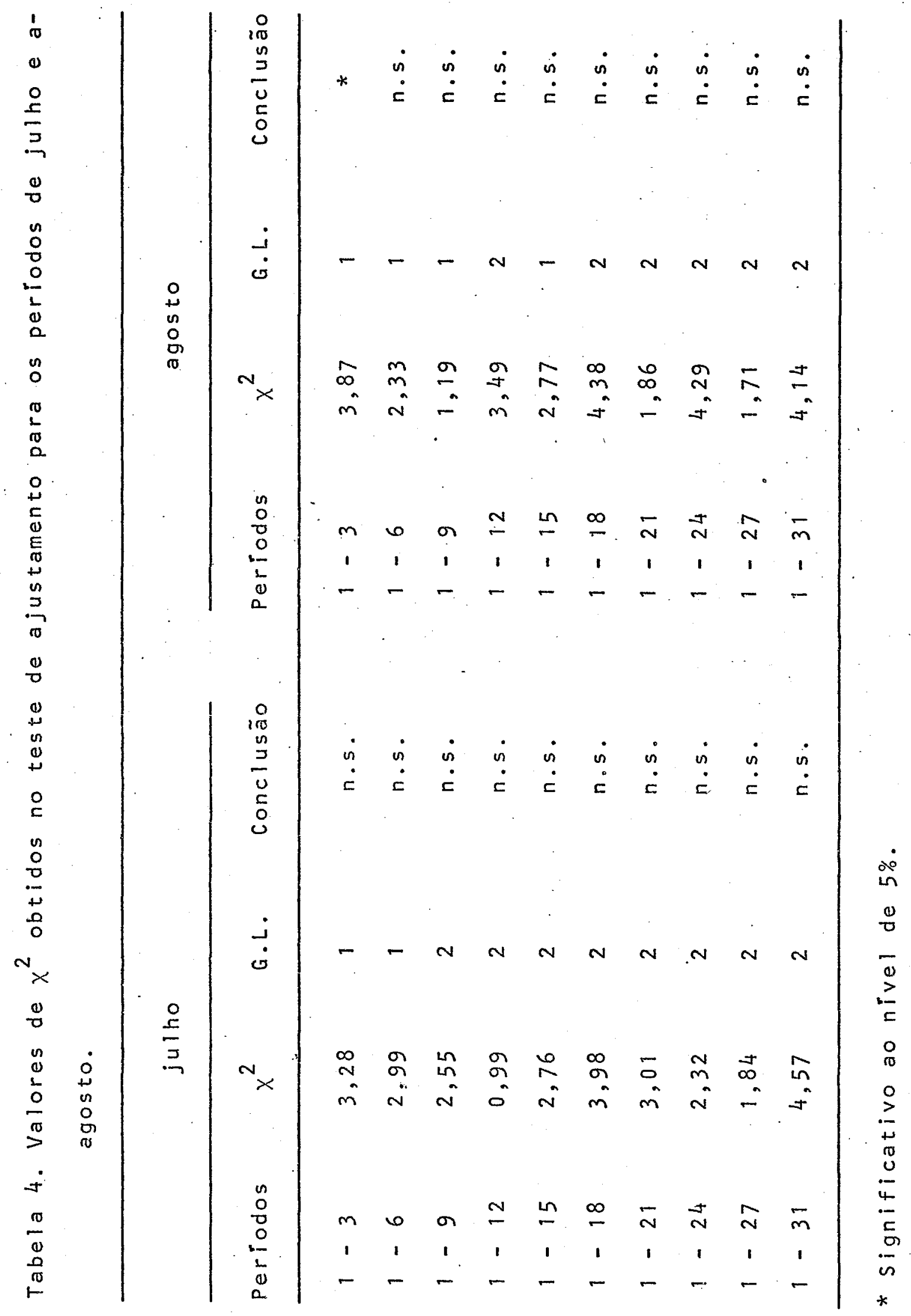


56.

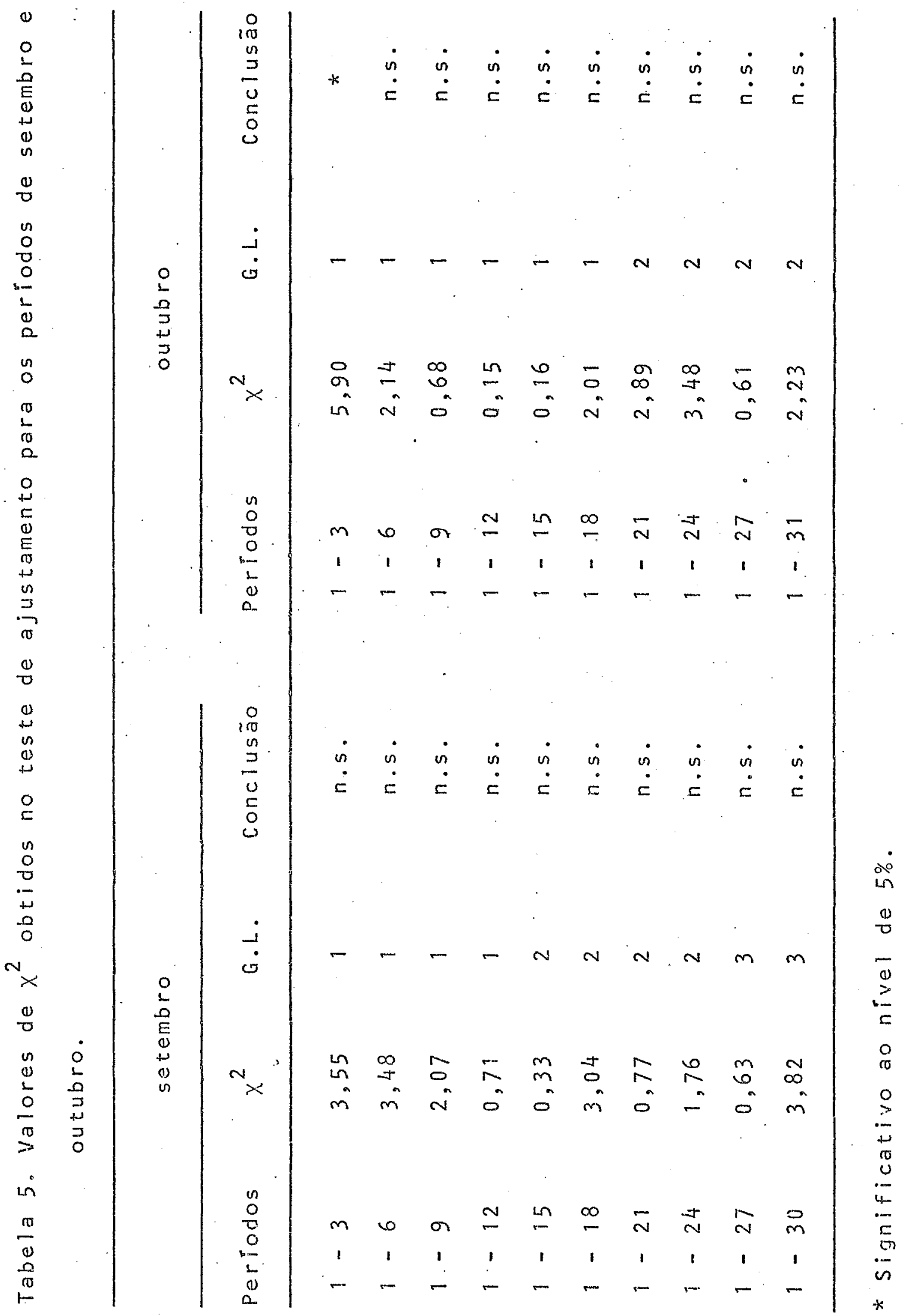




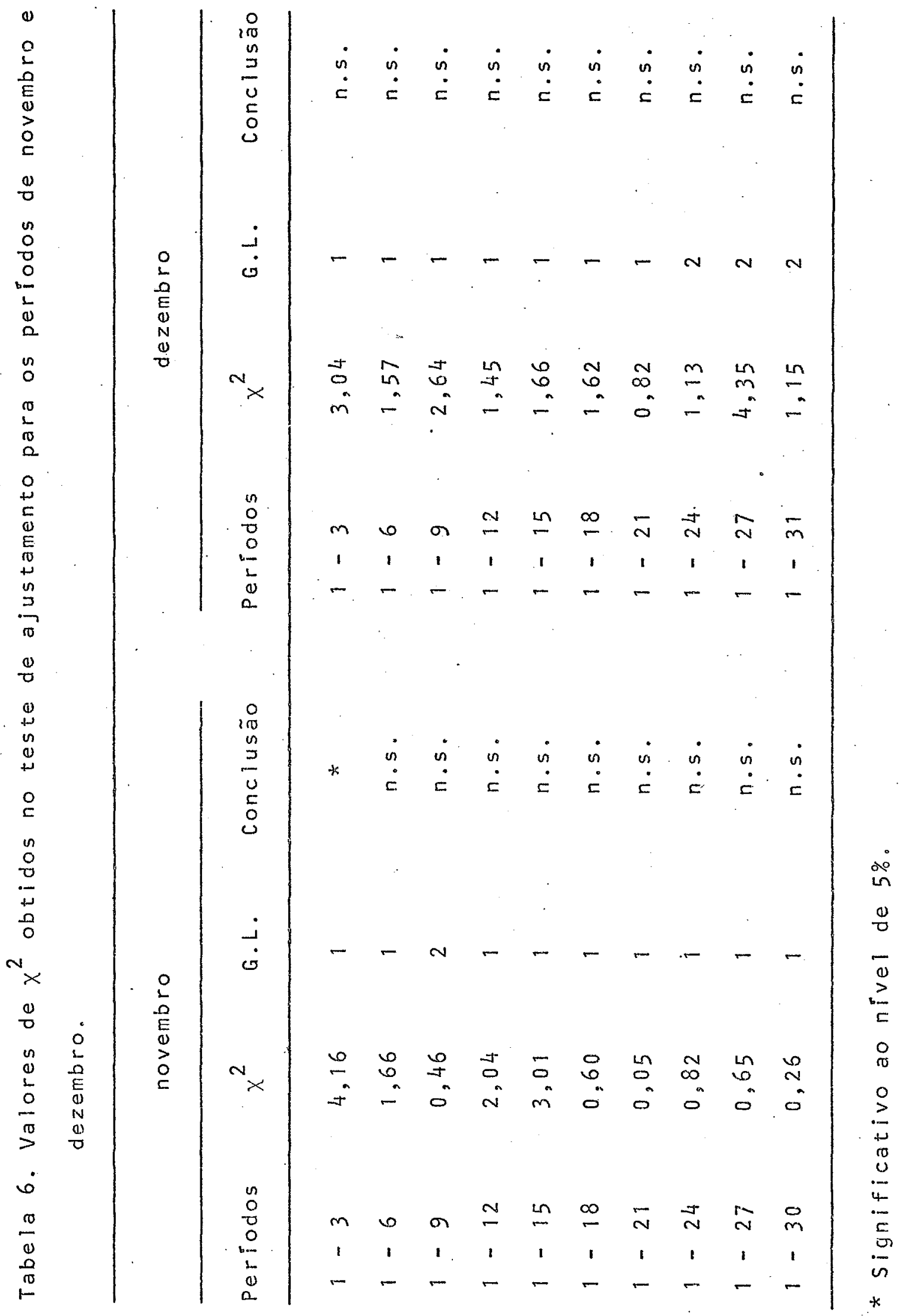




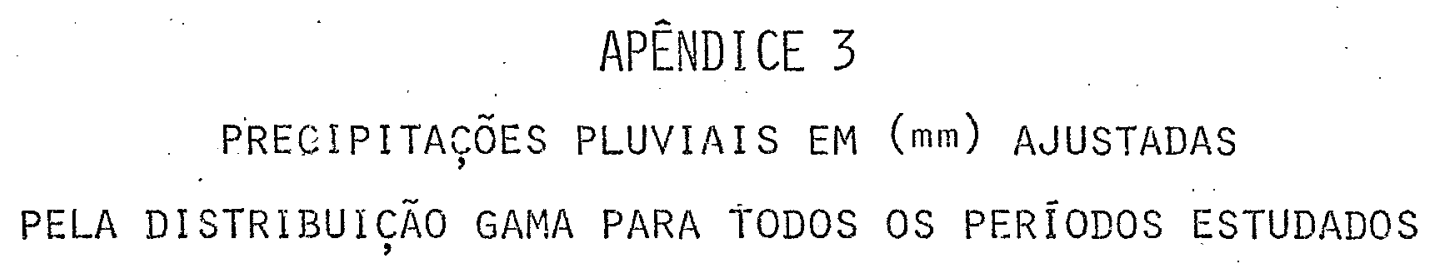


59.

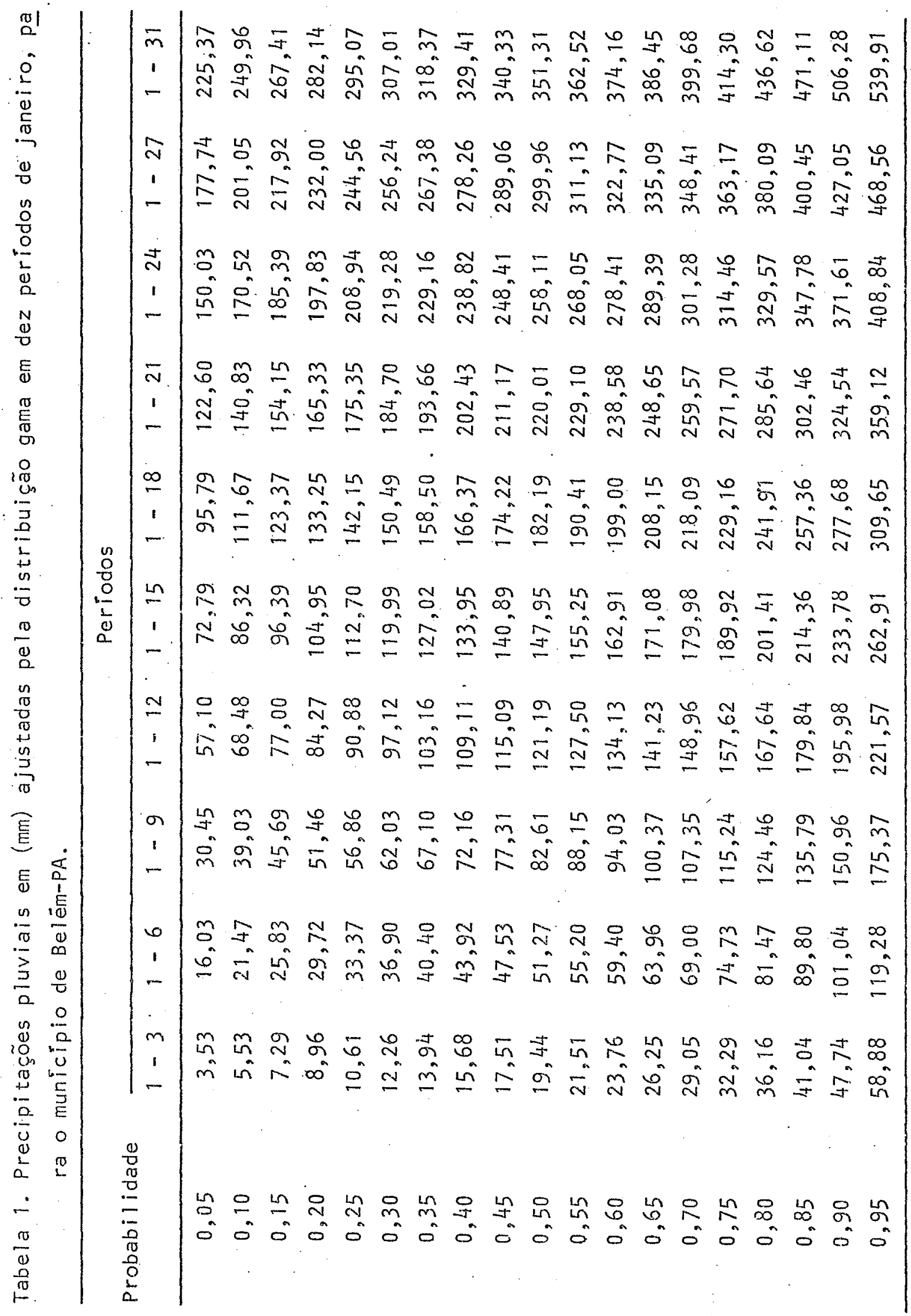


60.

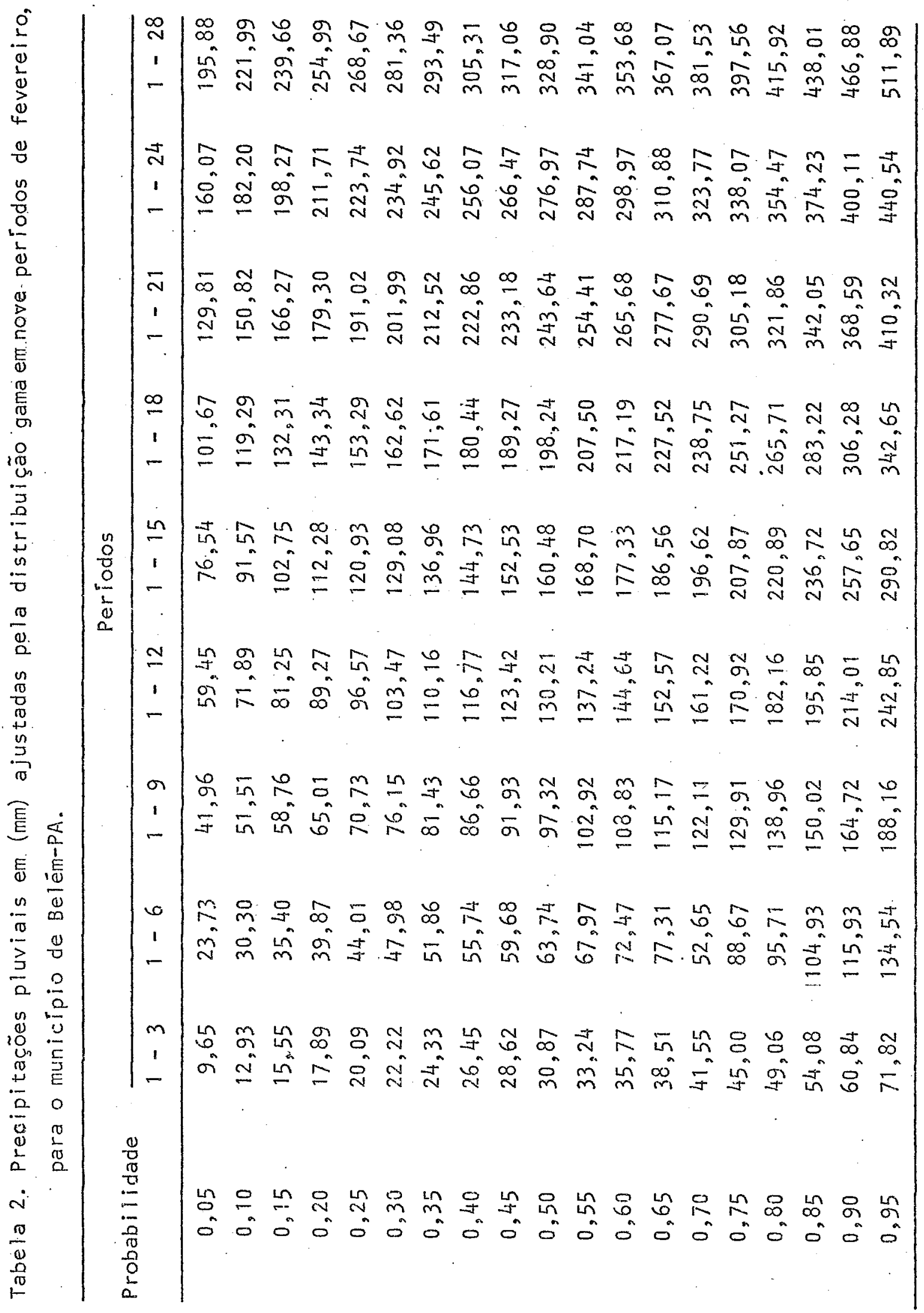




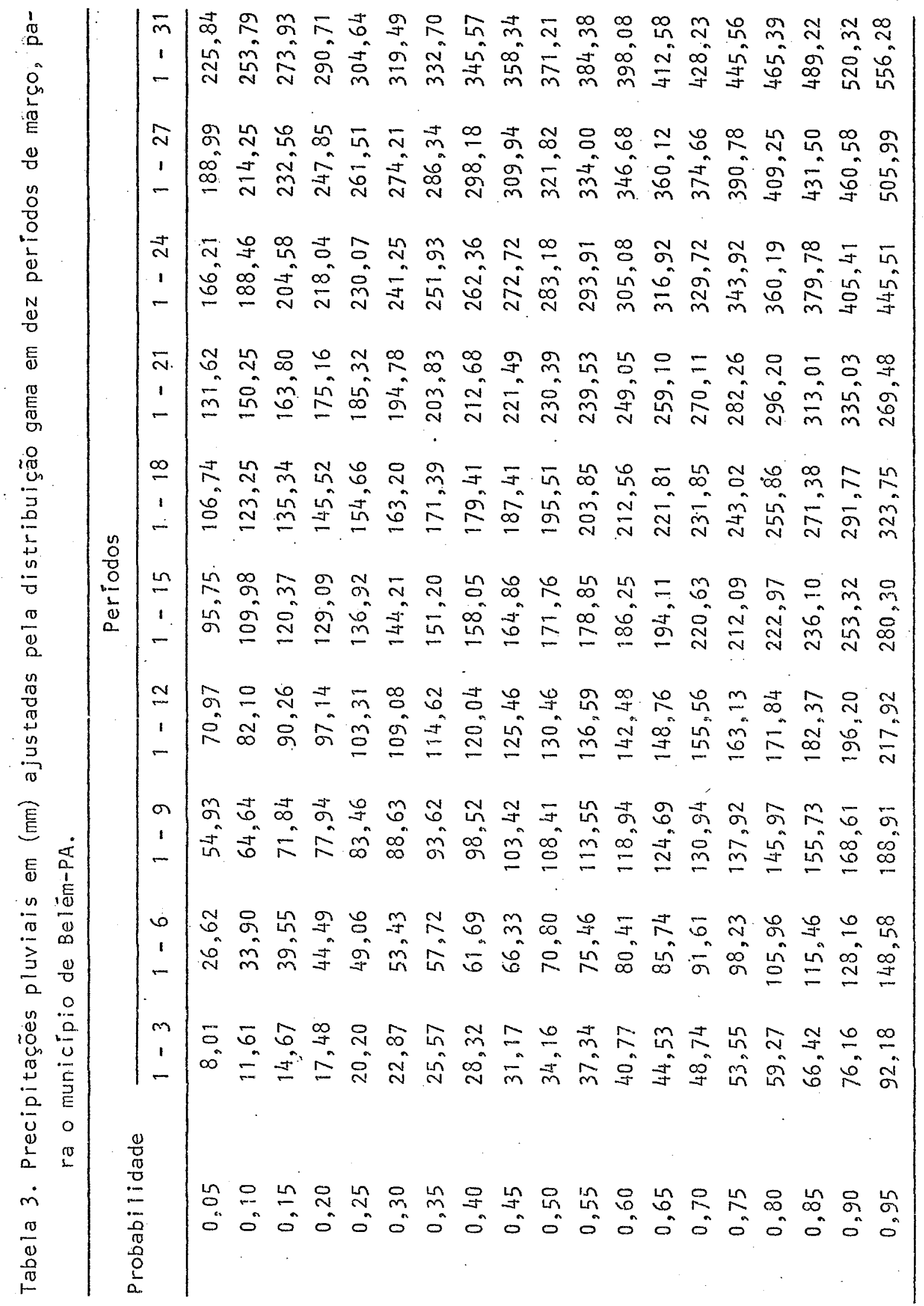


62.

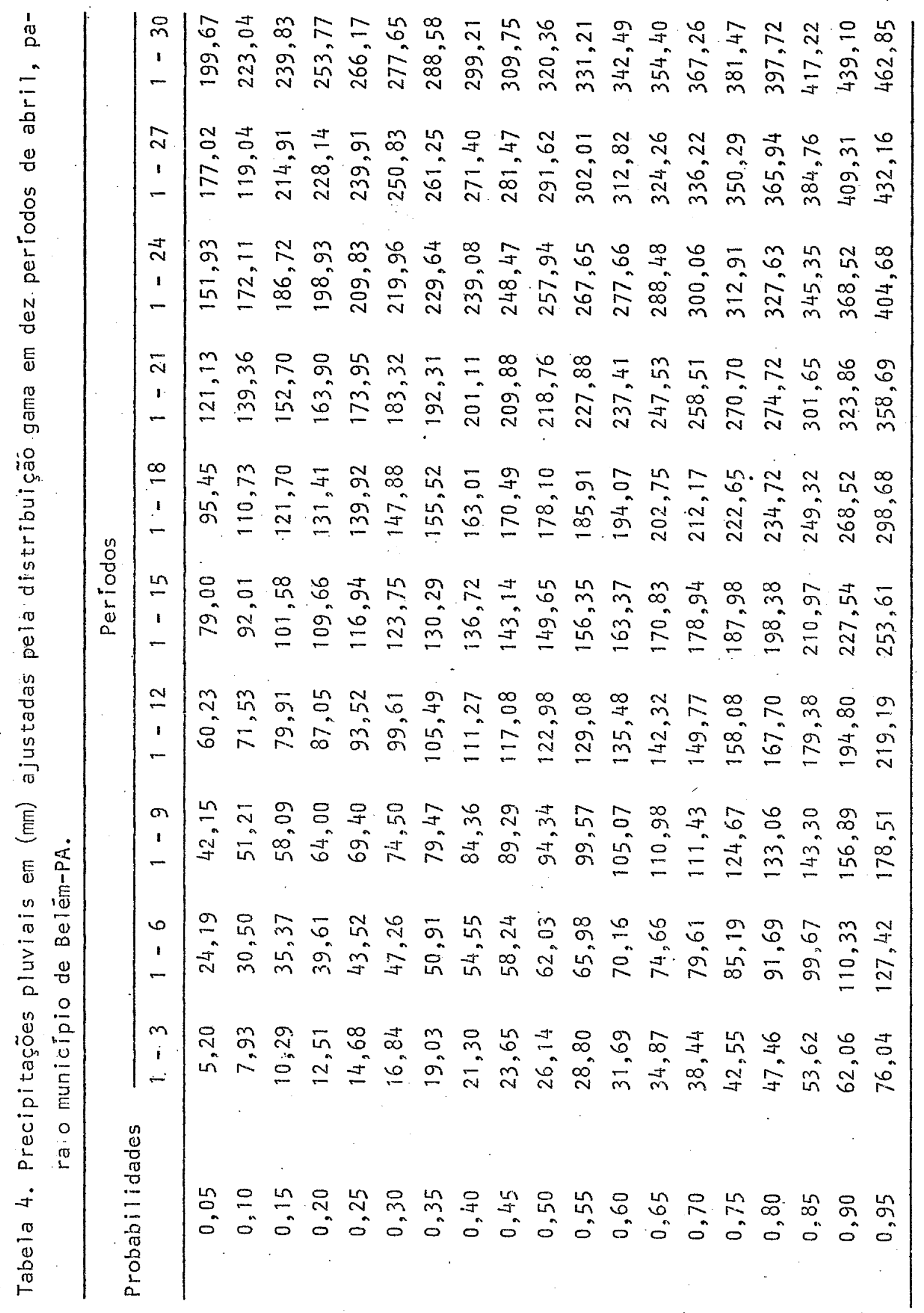


63.

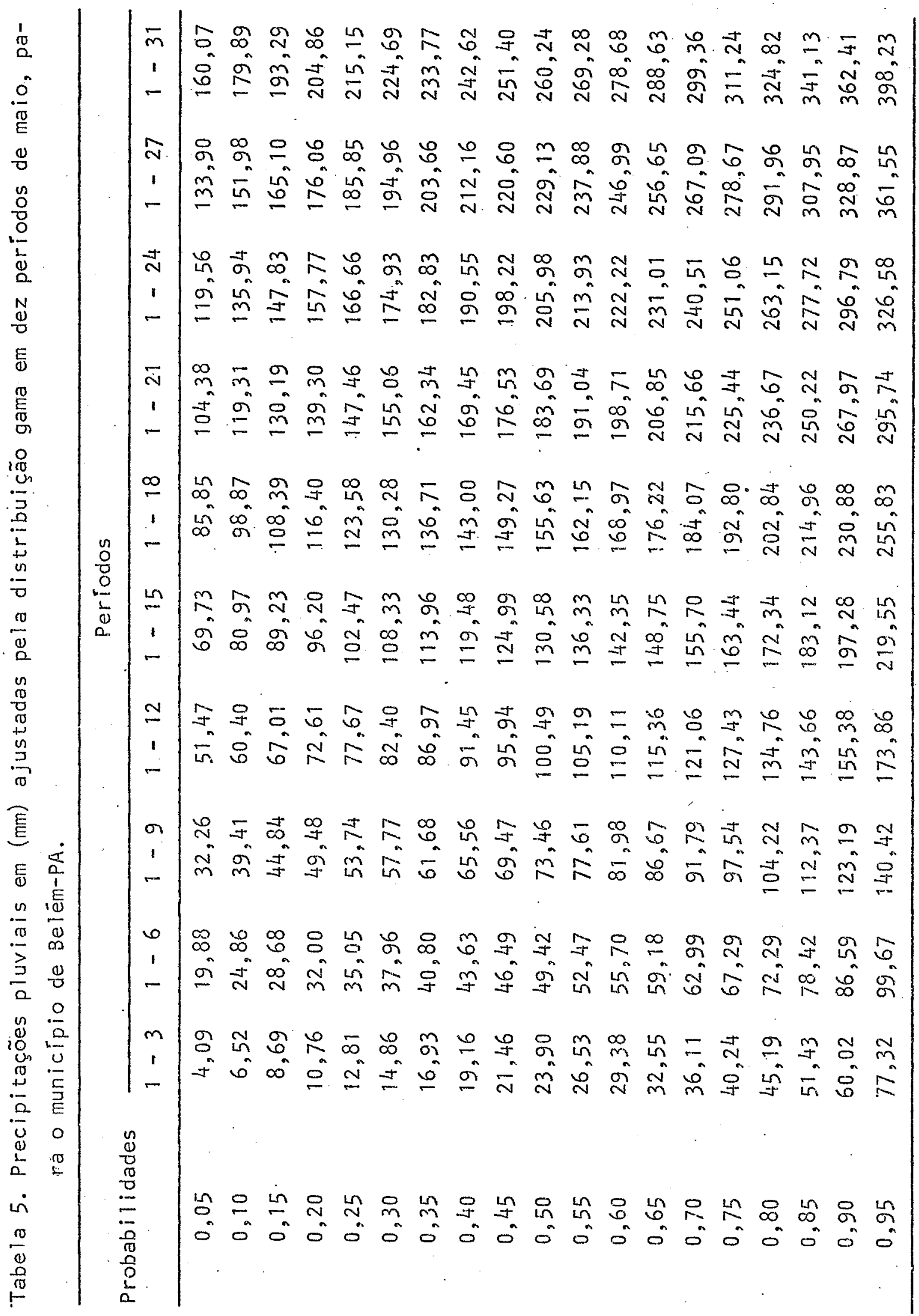


64.

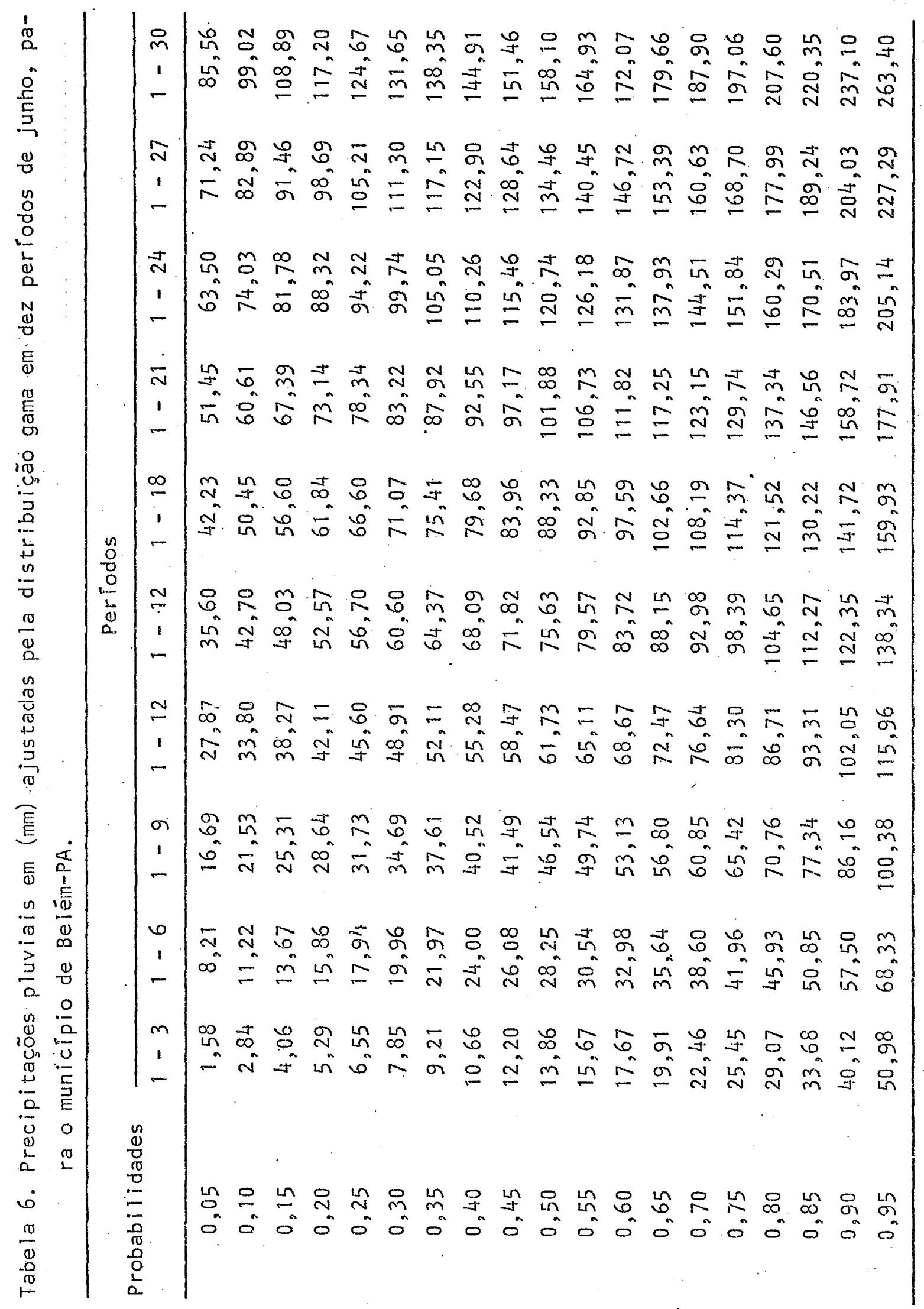


65.

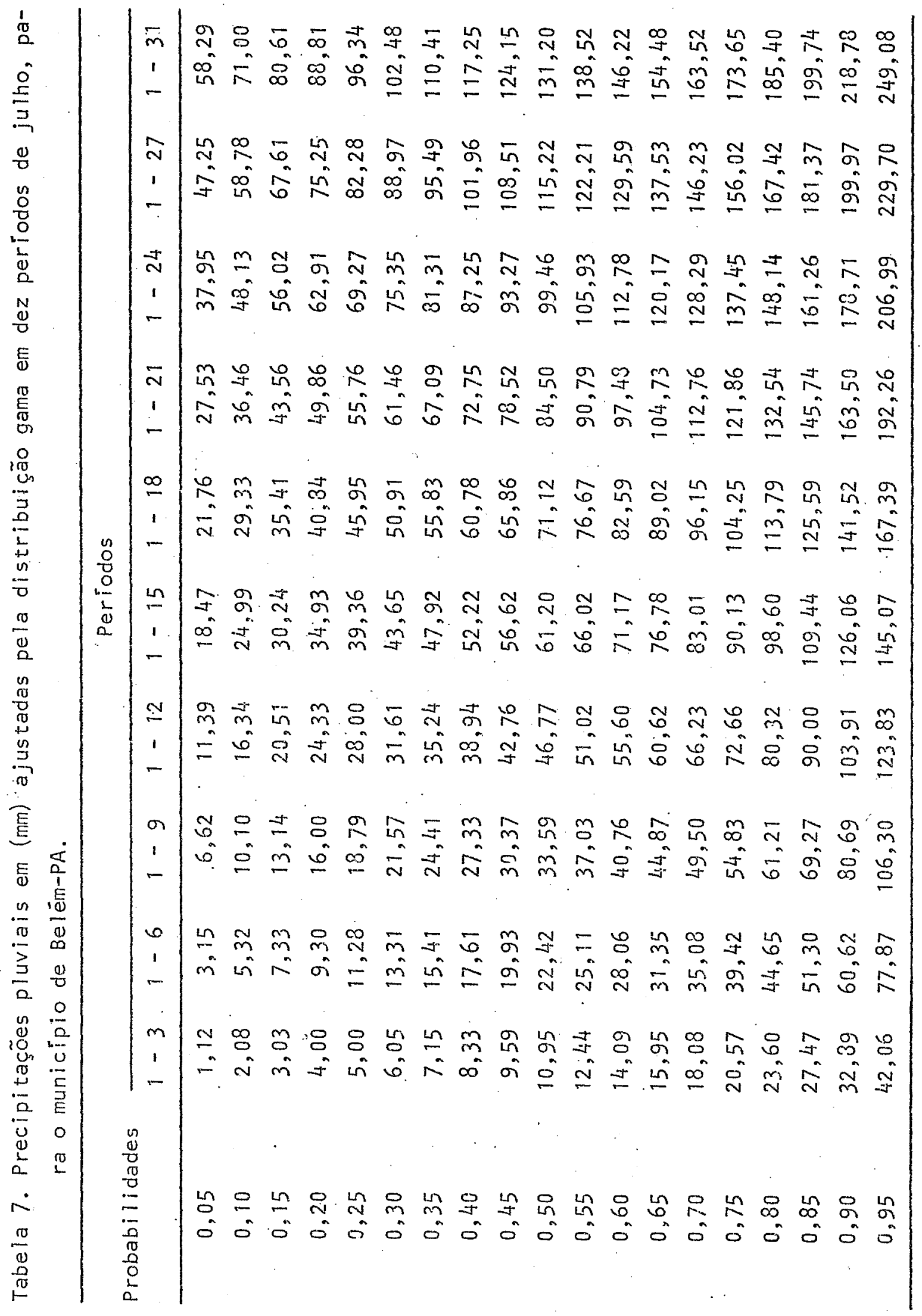


66.

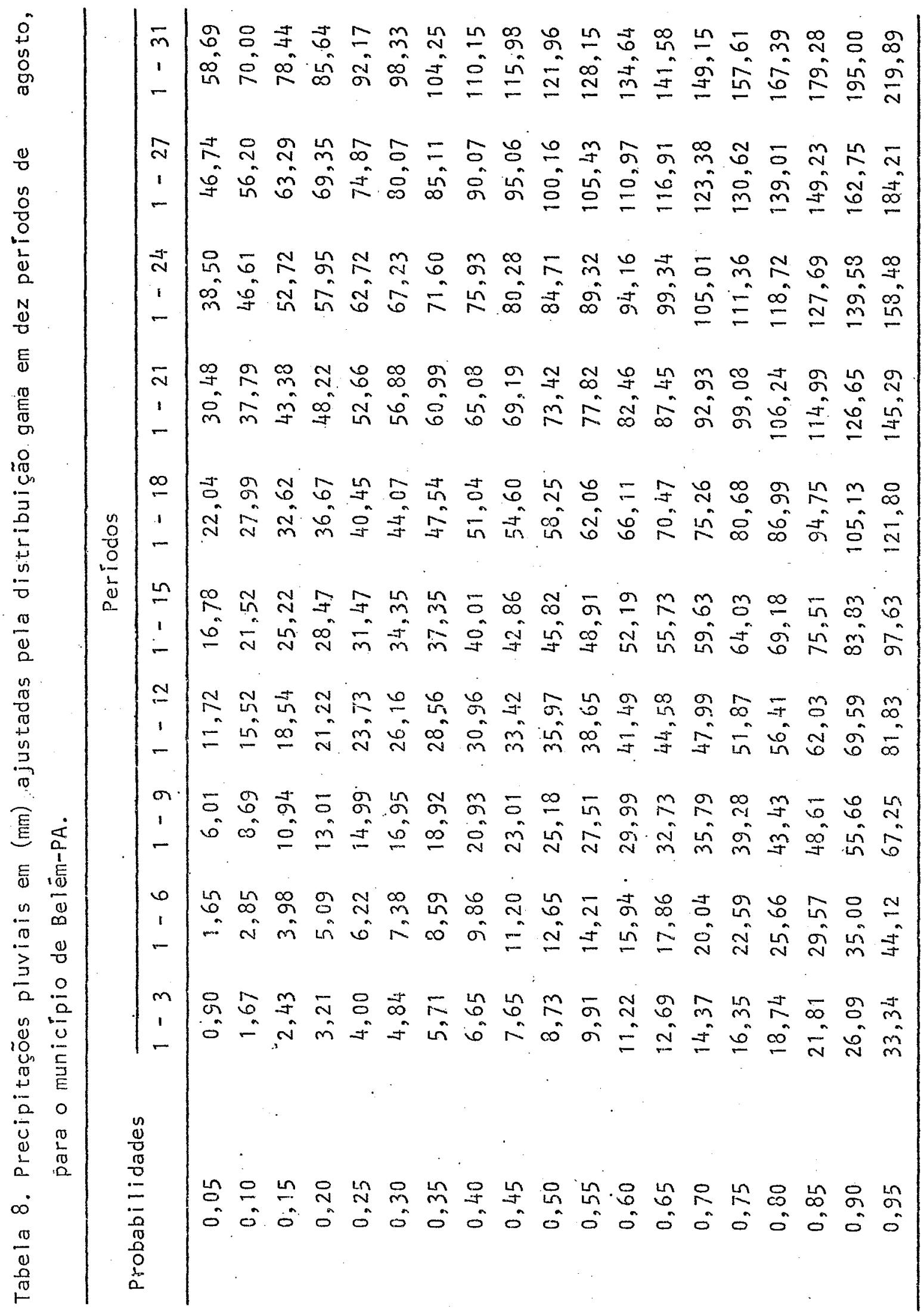




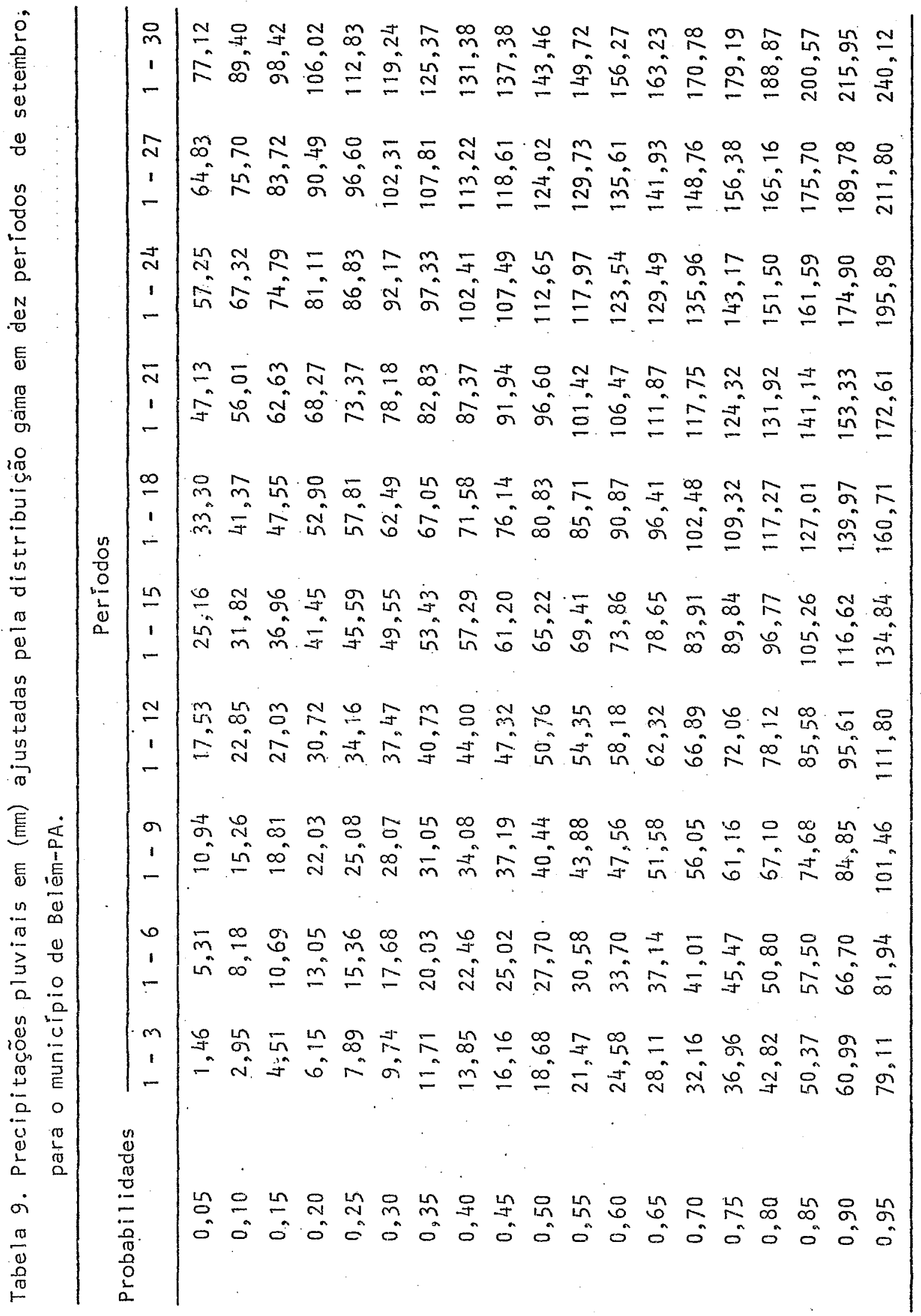


68.

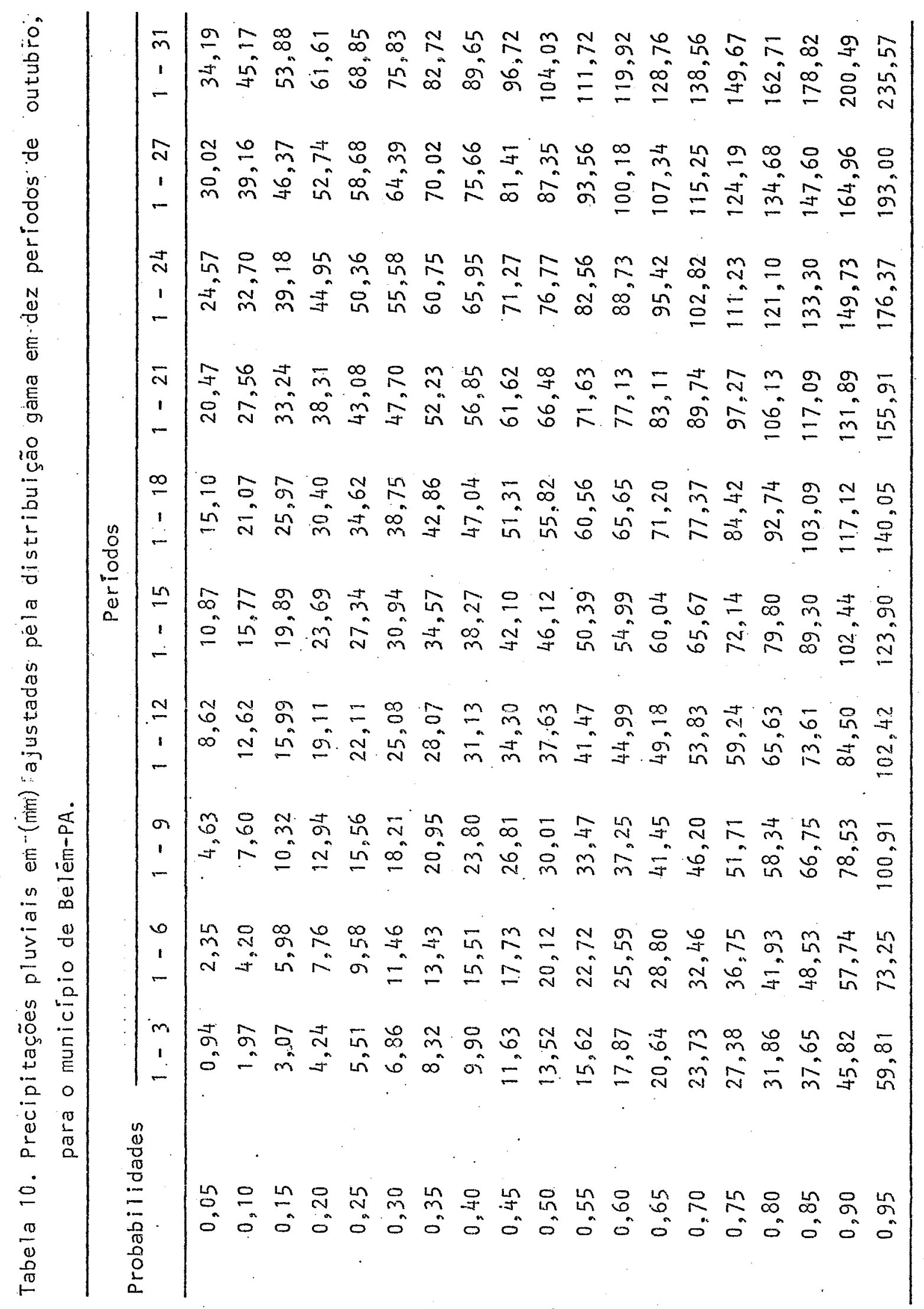


69.

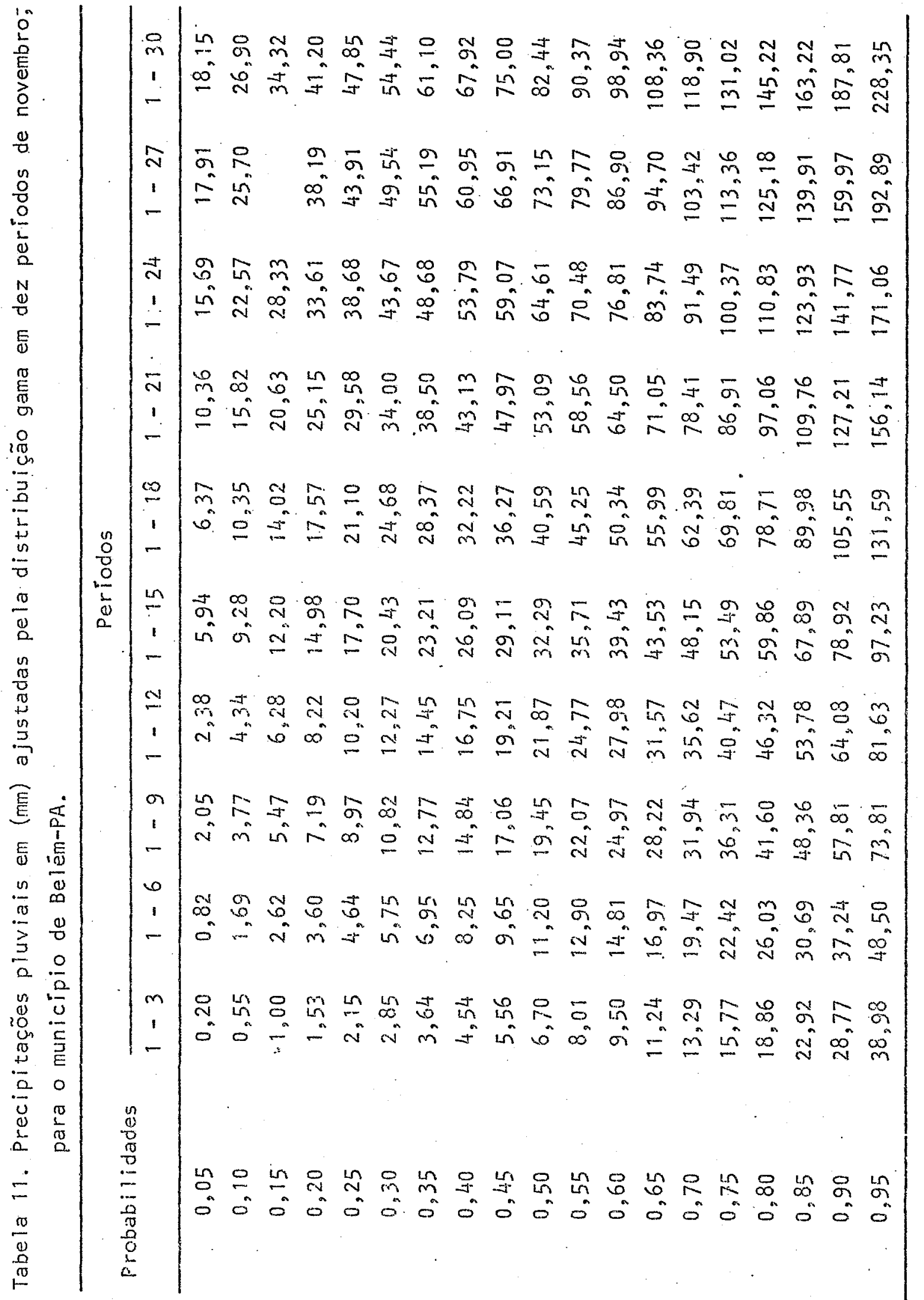


70.

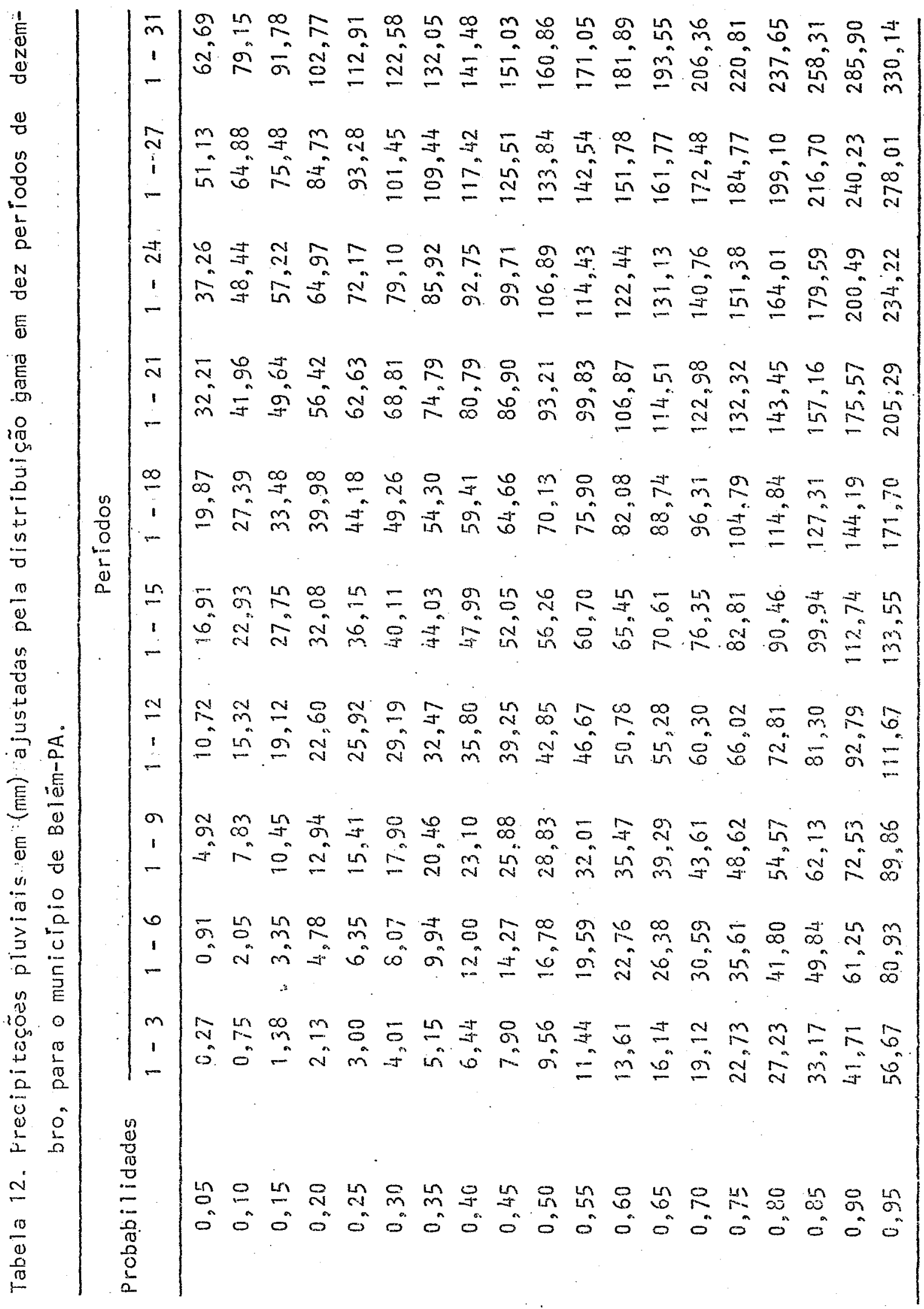

